\title{
Split-footed lacewings declined over time: indications from the morphological diversity of their antlion-like larvae
}

\author{
Gideon T. Haug ${ }^{1} \cdot$ Carolin Haug $^{1,2}$ (1) $\cdot$ Serita van der Wal ${ }^{1} \cdot$ Patrick Müller $^{3} \cdot$ Joachim T. Haug $^{1,2}$ (])
}

Received: 31 July 2020 / Accepted: 8 February 2021 / Published online: 20 June 2021

(c) The Author(s) 2021

\begin{abstract}
Nymphidae, the group of split-footed lacewings, is a rather species-poor group. Split-footed lacewings nowadays are restricted to Australasia, while fossil forms are also known from other areas of the world, indicating that the group was more speciesrich and therefore likely diverse in the past. Split-footed lacewings have rather distinct larvae, roughly resembling antlion larvae, but differing from the latter especially with regard to the mandibles. Antlion larvae usually have three prominent teeth on each mandible, while at least extant larvae of split-footed lacewings only have a single prominent tooth per mandible. Fossils interpreted as larvae of split-footed lacewings are well known from amber from Myanmar (ca. 100 myr; Burmese amber) and by a single specimen from Baltic amber (about $40 \mathrm{myr}$ ). We here report additional fossil specimens from Myanmar amber, expanding the known record of fossil forms from six depicted specimens to 15 . For the extant fauna, we could compile 25 larvae. We compare the diversity of shape of extant and fossil larvae through time using an outline analysis (based on elliptic Fourier transformation) of the head. The results of this analysis indicate that the morphological diversity, or disparity, of split-footed lacewing larvae was higher in the past than it is today. With this type of analysis, we can show a loss of diversity over time, without the necessity to identify the fossil larvae down to a narrow taxonomical range. A similar pattern has already been recognised in silky lacewings, Psychopsidae. This might indicate a general loss of diversity of lacewing larvae.
\end{abstract}

Keywords Nymphidae $\cdot$ Neuroptera $\cdot$ Myrmeleontiformia $\cdot$ Burmese amber $\cdot$ Cretaceous

\section{Introduction}

It is quite apparent that there is a decline of diversity inside the ecologically important group Insecta. To understand the causes behind this problem, we can learn from similar occurrences in the past. Such information is provided by the fossil record. We are able to compare the diversity of fossil insects from different time periods. Especially fossils in amber can be rather well compared to their modern counterparts, due to their almost life-like appearance.

Handling Editor: Mike Reich.

Joachim T. Haug

joachim.haug@palaeo-evo-devo.info

1 Biocenter, Ludwig-Maximilians-Universität München (LMU Munich), Großhaderner Str. 2, 82152 Planegg-Martinsried, Germany

2 GeoBio-Center at LMU, Richard-Wagner-Str. 10, 80333 Munich, Germany

3 Zweibrücken, Germany
A large share of the diversity of Insecta, in the modern fauna as well as in the past, is represented by the group Holo-metabola. More precisely, four major lineages within Holo-metabola are generally considered as hyper-diverse, also known as the big four: Diptera (e.g. flies, gnats, midges), Lepidoptera (e.g. moths), Coleoptera (beetles, weevils) and Hymenoptera (bees, ants and other wasps). Each of these four lineages includes more than 100,000 formally described species. Yet, there are also numerous smaller lineages in Holometabola. Some of them seem to have played a more important role in the past, i.e. during the early diversification of Holometabola as a whole. One of these lineages is Neuroptera.

In the modern fauna, we find about 6000 representatives of Neuroptera, also called lacewings including antlions and their kin. Most adult lacewings resemble adult moths or dragonflies in rough appearance. The larval forms of lacewings are, on the contrary, quite special. Most of these larvae are ambush predators, sitting and waiting for prey (e.g. Henry 1972). For the final catch, they use a pair of stylets. Each stylet is formed by the mandible and the maxilla on 
the same side. Both are elongated, the mandible has a distinct groove at the functionally lower side, which is covered by the very thin maxilla. By this, the two structures form a distinct channel. Through this channel, the larvae inject digestive liquid into their prey and suck the liquid content out. A well-known example for such larvae is the larval form of antlions. These are well known for digging funnels into sand to trap prey before piercing them with their stylets. Antlions and their closer relatives are representatives of the neuropteran in-group Myrmeleontiformia, the group of antlion-like lacewings.

The fossil record of larvae of antlion-like lacewings predates back to the late Early Cretaceous (Herrera-Flórez et al. 2020). Especially the slightly younger amber from Myanmar has yielded several fossils of these larvae (Xia et al. 2015; Wang et al. 2016; Liu et al. 2016, 2018; Zhang 2017; Badano et al. 2018; Haug et al. 2018, 2019a, b, c; Herrera-Flórez et al. 2020). In fact, many groups are represented by enough specimens to quantitatively compare these to their extant counterparts (Haug et al. 2020, accepted; Herrera-Flórez et al. 2020). Such comparisons revealed a loss in diversity of larval forms of Psychopsidae (silky lacewings; long-nosed antlions) and at least a loss of certain larval forms of Crocinae (thread-winged lacewings; long-necked lacewings).

Here, we focus on another in-group of Myrmeleontiformia, Nymphidae, the group of split-footed lacewings. The group is in the modern fauna restricted to Australasia and includes 35 formally described species (Oswald and Machado 2008). Fossil forms occurred in a much wider range, including for example South America and Europe (Shi et al. 2015), with a total of 23 formally described fossil species.

Adult spilt-footed lacewings are morphologically similar to other lacewings, but have a relatively wider posterior trunk (abdomen). Larval forms are also distinct. All larvae have a single prominent tooth on each mandible. There are two major lineages within Nymphidae, which can be easily recognised based on their larvae. Larvae of Nymphinae resemble antlion larvae in many aspects, live on the ground and use debris to camouflage themselves. Larvae of Myiodactylinae have a very broad, almost disc-shaped trunk. They live on plants, do not use debris, but several have short setae-bearing processes (scoli) (Shi et al. 2015).

We here compare the morphological diversity of larvae of split-footed lacewings through time. As the species identification of fossil holometabolan larvae is challenging (at best), we do not use measures based on taxonomic properties, but quantitatively compare the morphological diversity of the head.

\section{Materials and methods}

\section{Materials}

All newly reported fossil specimens are preserved in amber from the about 100-million-year-old Burmese deposits, Hukawng Valley, Kachin State, Myanmar (Cruickshank and Ko 2003). Material for this study came from different collections. Two specimens come from the collection of one of the authors (collection Müller BUB 0797, 3382a) and are available for further study on request. One specimen is deposited in the Staatliche Naturwissenschaftliche Sammlungen Bayerns-Bayerische Staatssammlung für Paläontologie und Geologie in Munich under repository number SNSBBSPG 2020 XCIII 18 (originally from the collection of one of the authors: collection Müller BUB 1518). Seven specimens are deposited in the collection of the Palaeo-Evo-Devo Research Group Collection of Arthropods, LMU (LudwigMaximi-lians-Universität) Munich, Germany (PED 0377, 0423, 0458, 0474, 0532, 0579, 0665). All PED specimens were legally purchased on ebay.com from various traders (burmite-miner; burmitefossil; macro-cretaceous). All extant specimens that were available in the literature were included for comparison (see below).

\section{Documentation methods}

Documentation was performed on a Keyence VHX 6000 digital microscope. We photographed each specimen from both sides (if accessible), once illuminated by coaxial crosspolarised light (Haug et al. 2013a) and once by unpolarised ring light. Under both illuminations, documentation was performed with a white and a black background. The built-in HDR function was used to optimise the images (cf. Haug et al. 2013b). Image stacks were recorded to overcome limitations in depth of field; several adjacent stacks were recorded to overcome limitations in field of view (Haug et al. 2008, 2011). The images providing the best contrast were used.

\section{Image processing}

Images recorded on the Keyence VHX 6000 digital microscope were processed automatically by the built-in software. Adobe Photoshop CS2 and CS3 were used for optimising all images (histograms, saturation, sharpness).

\section{Presentation}

All visible structures of the fossils were colour-marked to provide an interpretation of the structures. Adobe Illustrator 
CS2 was used to re-draw split-footed lacewing larvae from literature. The drawings were slightly simplified; corresponding structures were given the same colours.

\section{Shape analysis}

All accessible heads (including head capsule and mandibulomaxillary stylets) were re-drawn by hand in Adobe Illustrator CS2. The better preserved half was drawn and mirrored. The resulting image was checked against the original to reduce possible artefacts. Dorsal and ventral view was used, although there are slight differences. The important criterion was a well-accessible posterior rim of the head capsule. Redrawn images were analysed in SHAPE (see also Braig et al. 2019; Haug et al. 2020 for details).

\section{Morphospace occupation}

Values were plotted in OpenOffice, and plots were re-drawn in Adobe Illustrator CS2. We compared the diversity of head shape of extant and fossil larvae. For each, the range of occupation of the dominating assembled dimensions (principal components) was plotted and compared.

\section{Results}

\section{Extant larval representatives of Nymphidae depicted in the literature}

While early publications mention larvae of the group Nymphidae, they have not been figured (Brauer 1867; McLachlan 1871; Hagen 1873). This also applies to some later publications (e.g. Gallard 1935). A special case is Froggatt (1902), where the author described the life history of Nymphes myrmeleonides. Yet, we could find no images in this publication. Still, one specimen from this work seems to have been figured in a later publication (Froggatt 1907, see below; see discussion in MacLeod 1964).

All occurrences of depictions are listed chronologically. Cases in which the same specimen has been re-figured are also included chronologically, with reference to the original occurrence. While this includes a certain redundancy, it should represent the most complete way of cross-referencing, avoiding interpreting the same specimen as two independent occurrences.

Froggatt (1907) — provided a drawing of a larval representative of Nymphidae (his fig. 36) in dorsal view (specimen 1; Fig. 1). Although the author interpreted it as the larva of Porismus strigatus, this seems incorrect (MacLeod 1964: 345). The drawing is not very detailed and symmetric, indicating a certain degree of idealisation. Still, the drawing appears to be based on an actual specimen. No indication of size was provided.

Weele (1908) — provided a drawing of a larval representative of Nymphidae (his fig. 157) in dorsal view (specimen 2; Fig. 1). The author interpreted it as the larva of Acmonotus sabulosus, but this seems incorrect (MacLeod 1964: 348). The drawing is symmetric, indicating a certain degree of idealisation. Still, the drawing appears to be based on an actual specimen. No indication of size was provided.

Tillyard (1926) — provided a drawing of a larval representative of Osmylops pallidus (his fig. U17) in dorsal view (specimen 3; Fig. 1). The drawing is symmetric, indicating a certain degree of idealisation. Still, the drawing appears to be based on an actual specimen. According to figure caption, the specimen was $6.5 \mathrm{~mm}$ in overall length.

Ross (1953)—provided a photograph of a larva of the group Osmylops (his unnumbered figure on page 46) in dorsal view (specimen 4; Fig. 1). The specimen was apparently stored in the collections of the California Academy of Sciences (MacLeod 1964: 351). It was later restudied, and additional details are given in MacLeod (1964; see next point). Based on the information in MacLeod (1964), the specimen had an overall length of $10 \mathrm{~mm}$.

MacLeod (1964) — provided drawings of two larval specimens of Nymphidae. The first is a larva of Nymphes myrmeleonides, possibly a third instar (specimen 5; Fig. 1). Images include a dorsal view of the anterior body region (pl. XXIV, fig. 73); a ventral view of the anterior body region (pl. XXV, fig. 74); a lateral view of the head region (pl. XXVI, fig. 75); close-up of the labium (pl. XXVI, fig. 76); part of the mandible (pl. XXVI, fig. 77); and part of the maxilla (pl. XXVI, fig. 78). The author stated that he had seven specimens, representing different instars (p. 351); however, it appears that the drawings are mostly based on one actual specimen. According to the scale, the length of the head was $3.02 \mathrm{~mm}$.

The second specimen is possibly a larva of the group Osmylops, possibly a third instar. According to the text, this is specimen 4, i.e. it is the same as the one depicted in Ross (1953). Images include a dorsal view of the anterior body region (pl. XXVII, fig. 79) and a ventral view of the anterior body region (pl. XXVIII, fig. 80). MacLeod stated that he had ten specimens in total (p. 351). Still, most of the drawing is based on the single specimen depicted by Ross (1953). Six other specimens seem to have been deposited in the Sydney Museum, originally collected by Tillyard.

Riek (1970)—provided drawings of two specimens of larval representatives of Nymphidae. The first specimen (p. 491, fig. 29.12B, drawn by M. Quick; specimen 6; Fig. 1) was labelled "Nymphidae". In the text, it was indirectly indicated that it is of the so-called myrmeleontid type (p. 492) and stated to be a later instar. No indication of size was provided. The second specimen (p. 493, fig. 29.13, drawn by R. Erwins; specimen 7; Fig. 1) was labelled "myiodactylid 

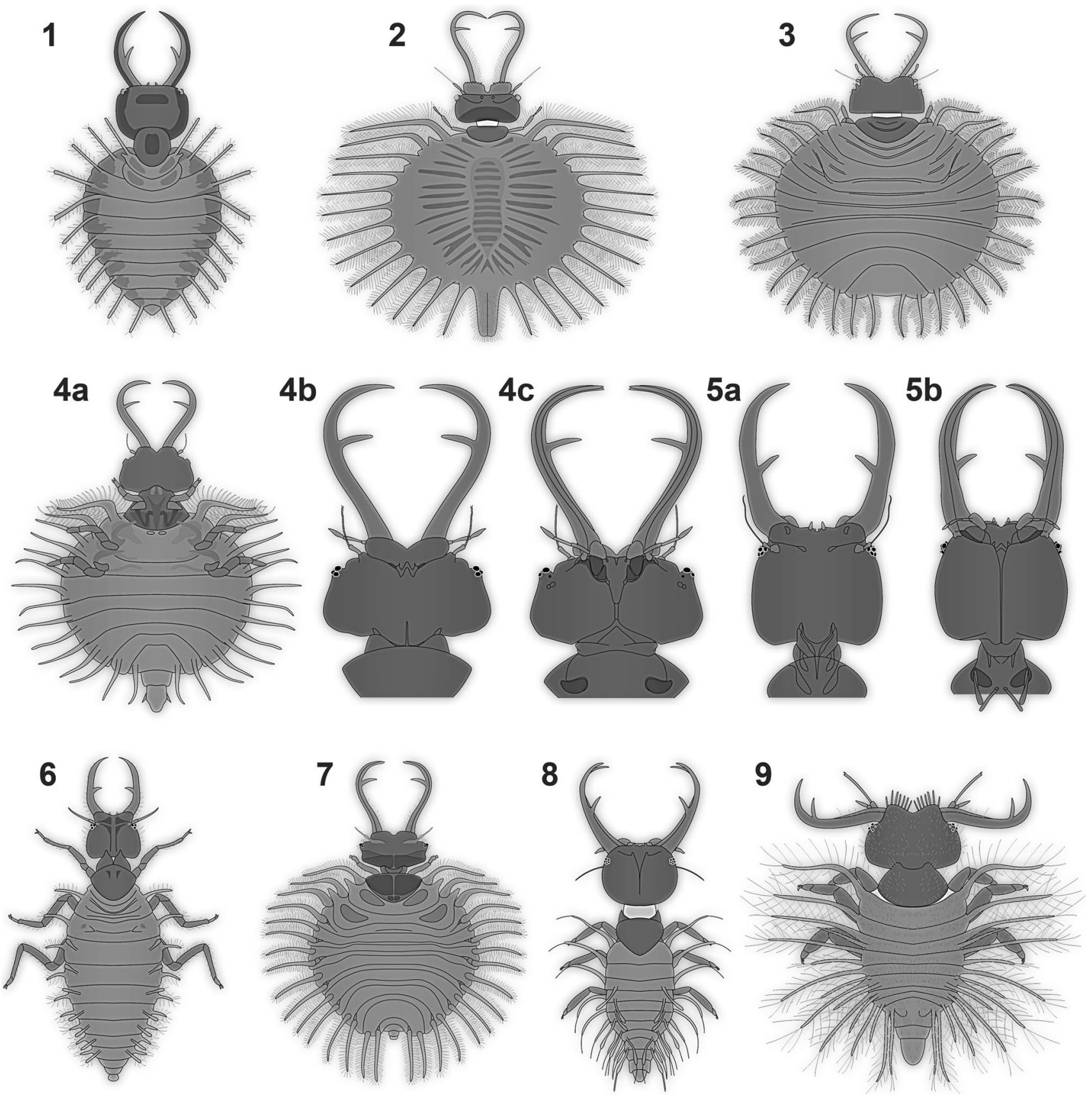

Fig. 1 Interpretive restorations of extant larvae of Nymphidae. The numbers on the figure correspond to the specimen numbers used in the main text; an exception is $30 \mathrm{~b}$ (see below). 1. Modified after Froggatt (1907: fig. 36). 2. Modified after Weele (1908: fig. 157). 3. Modified after Tillyard (1926: fig. U17). 4a. Modified after Ross (1953: 46). 4b. Modified after MacLeod (1964: fig. 79). 4c. Modified after MacLeod (1964: fig. 80). 5a. Modified after MacLeod (1964: fig. 73). 5b. Modified after MacLeod (1964: fig. 74). 6. Modified after Riek (1970: fig. 29.12B). 7. Modified after Riek (1970: fig. 29.13). 8. Modified after New (1982: fig. 1). 9. Modified after New (1983: fig. 3). 10-12. Modified after New and Lambkin (1989). 10. Their fig. 1. 11. Their fig. 2. 12. Their fig. 3. 13-17. Modified after Aspöck and Aspöck (2007: fig. 153). 18. Modified after Badano et al. (2017: fig. 1E), amended from the database "Atlas of Living Australia" (ala.org.au), catalogue number iNaturalist Australia

9714736. 19. Modified after the database "Atlas of Living Australia" (ala.org.au), catalogue number iNaturalist Australia 32152668. 20-25. Drawings are based on images from the database "Atlas of Living Australia" (ala.org.au). 20. Modified after catalogue number iNaturalist Australia 27397806. 21. Modified after catalogue number iNaturalist Australia 34194103. 22. Modified after catalogue number bowerbird 100717. 23. Modified after catalogue number bowerbird 41396. 24. Modified after catalogue number iNaturalist Australia 37327165. 25. Modified after catalogue number iNaturalist Australia 27688249. 26. Modified after MacLeod (1970: fig. 6). 27, 28. Modified after Xia et al. (2015). 27. Their p. 98, lower right. 28. Their p. 98, lower left. 29. Modified after Wang et al. (2016: suppl-fig. 3F). 30a. Modified after Badano et al. (2018: 5, fig. 3c). 30b. Modified after a reconstruction in Badano et al. (2018: 10, fig. 4iv) 
type" in the captions. According to the provided scale, the specimen has an overall body length of $8.95 \mathrm{~mm}$. Both drawings are quite detailed and seem to be based on actual specimens.

Both specimens have been re-figured several times, including in Gepp (1984), New $(1989,1991)$ and Tauber et al. (2003).

New (1982)—provided a drawing of a larval representative of Nymphes myrmeleonides (his p. 82, fig. 1) in dorsal view (specimen 8; Fig. 1). The specimen was stated to be a first instar. The drawing is detailed and asymmetric, indicating that the drawing is based on an actual specimen. According to the provided scale, the specimen has an overall body length of $5.26 \mathrm{~mm}$. Additional figures showed details of this and another specimen, which was not depicted sufficiently to be included into our analysis; all details were presented as drawings. Details of first instar include: margin of the head (p. 83, figs. 2, 3), labial palp (p. 83, fig. 4), antenna (p. 83, fig. 5), ventral details of head (p. 83, fig. 6), eyes (p. 84, fig. 7), lateral processes (p. 84, fig. 8), tarsal claw (p. 84, fig. 9), and trunk end (p. 84, fig. 10). Details of the third instar include (all on p. 84): margin of the head (fig. 11), tip of the mandible (fig. 12), tip of the maxilla (fig. 13), and labial palp (fig. 14).

New (1983) — provided a drawing of a larval representative of Osmylops sejunctus (his p. 122, fig. 3) in dorsal view (specimen 9; Fig. 1). The specimen was stated to be a first instar. The drawing is detailed and asymmetric, indicating that the drawing is based on an actual specimen. According to the provided scale, the specimen has an overall body length of $2.46 \mathrm{~mm}$. Additional figures showed details of the chorion (p. 122, fig. 1) and the oviruptor (p. 122, fig. 2) as drawings. Photographs of first instar individuals were also shown (p. 123, figs. 4, 5), yet it remains unclear whether these show the same individual as in fig. 3. We therefore cannot consider these two images further. Details of a first instar were also provided as drawings (all on p. 124): details of setae and other ornamentation (figs. 6-9), antenna (fig. 10), labial palp (fig. 11), details of the trunk (fig. 12), and a tarsal claw (fig. 13).

Gepp (1984)-re-figured specimens 6 and 7, i.e. the specimen from Riek (1970). Specimen 7 (his p. 200, pl. 9, fig. 19a) was labelled "Nymphidae (myiodactylider Typ?)"; specimen 6 (his p. 200, pl. 9, fig. 19b) was labelled "Nymphidae (myrmeleonider Typ?)".

New (1989)-re-figured specimens 6 and 7, i.e. the two drawings from Riek (1970). Specimen 6 was labelled as "Nymphes sp." (p. 102, fig. 146A), specimen 7 was labelled as "Osmylops sp." (p. 102, fig. 146B). Riek (1970) was also cited as the source.

New and Lambkin (1989) — provided images of three larval representatives of Norfolius howensis. The first specimen (p. 94, fig. 1) was shown as a photograph in dorsal view (specimen 10; Fig. 1). It was stated to be a first instar. According to the provided scale, the specimen has an overall body length of $4.42 \mathrm{~mm}$.

The second specimen (p. 94, fig. 2) was shown as a photograph in dorsal view (specimen 11; Fig. 1). It was stated to be a third instar. According to the provided scale, the specimen has an overall body length of $10.57 \mathrm{~mm}$.

The third specimen (p. 95, fig. 3) was shown as a drawing in dorsal view (specimen 12; Fig. 1). It was stated to be a third instar. It differs clearly from the second specimen, indicating that it is indeed another specimen and not a second figure of the same specimen. According to the provided scale, the specimen has an overall body length of $9.59 \mathrm{~mm}$.

Additional figures show details as drawings (all on p. 95): stylet of first instar (fig. 4); antenna of third instar (fig. 5); parts of stylet of third instar (figs. 6, 7); labial palp of the third instar (fig. 8); anterior head rim of the third instar (fig. 9); and setae along the margin on the head of the third instar (fig. 10).

New (1991)—re-figured specimens 6 and 7, i.e. the two drawings from Riek (1970). Specimen 7 was labelled as "nymphid (myiodactylid type)" (p. 540, fig. 34.12F), specimen 6 was labelled as "nymphid" (p. 540, fig. 34.12G). As sources, R. Ewins and M. Quick were cited.

Tauber et al. (2003)—re-figured specimens 6 and 7, i.e. the two drawings from Riek (1970). Specimen 7 was labelled as "Nymphidae (Myiodactylinae)" (p. 790, fig. 5e), specimen 6 was labelled as "Nymphidae (Nymphinae)" (p. 790, fig. 5f). As a source, New (1991) was cited.

Aspöck and Aspöck (2007)—provided a photograph (their p. 106, fig. 153) of a total of five larval representatives of Osmylops sejunctus. All specimens were shown in dorsal view. According to figure captions, the image was originally provided by Peter Duelli. We numbered them here clockwise for further referencing (Fig. 1) starting with the lower left (specimen 13), upper left (specimen 14), upper middle (specimen 15), upper right (specimen 16) to the lower right (specimen 17). The fact that five specimens are close together is an indication that these are rather newly hatched forms. After hatching, most lacewing larvae will disperse and show a strongly territorial behaviour against conspecific larvae.

Shi et al. (2015)—re-figured specimens 6 and 7, i.e. the two drawings from Riek (1970). Specimen 7 was labelled as "Myiodactylinae" (p. 460, fig. 4 lower), specimen 6 was labelled as "Nymphinae" (p. 460, fig. 4 upper). No source was cited, image credit was given to CSIRO (probably the copyright holder).

Badano et al. (2017) — provided a photograph (their p. 96, fig. 1F) of a larval representative of Nymphidae (specimen 18; Fig. 1) in dorsal view. The specimen was labelled as "cf. Osmylops, larva, Nymphidae: Miodactylinae" [sic]. 

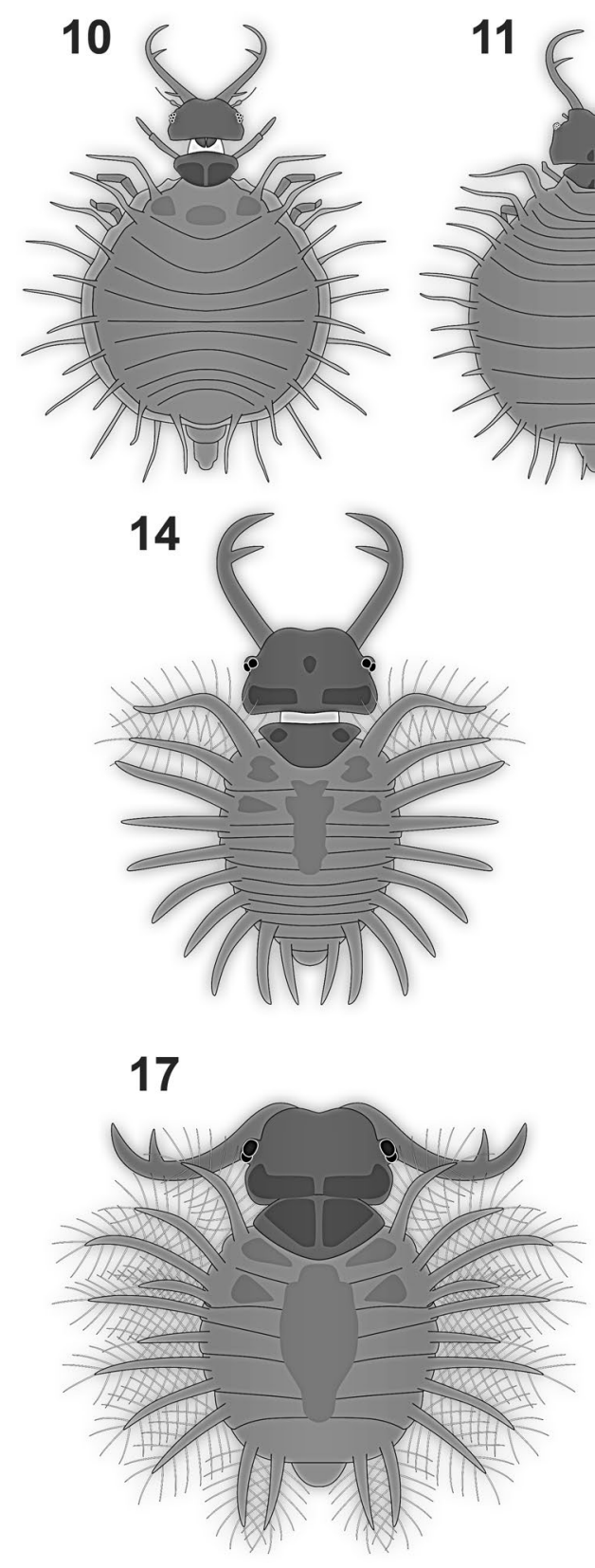

18
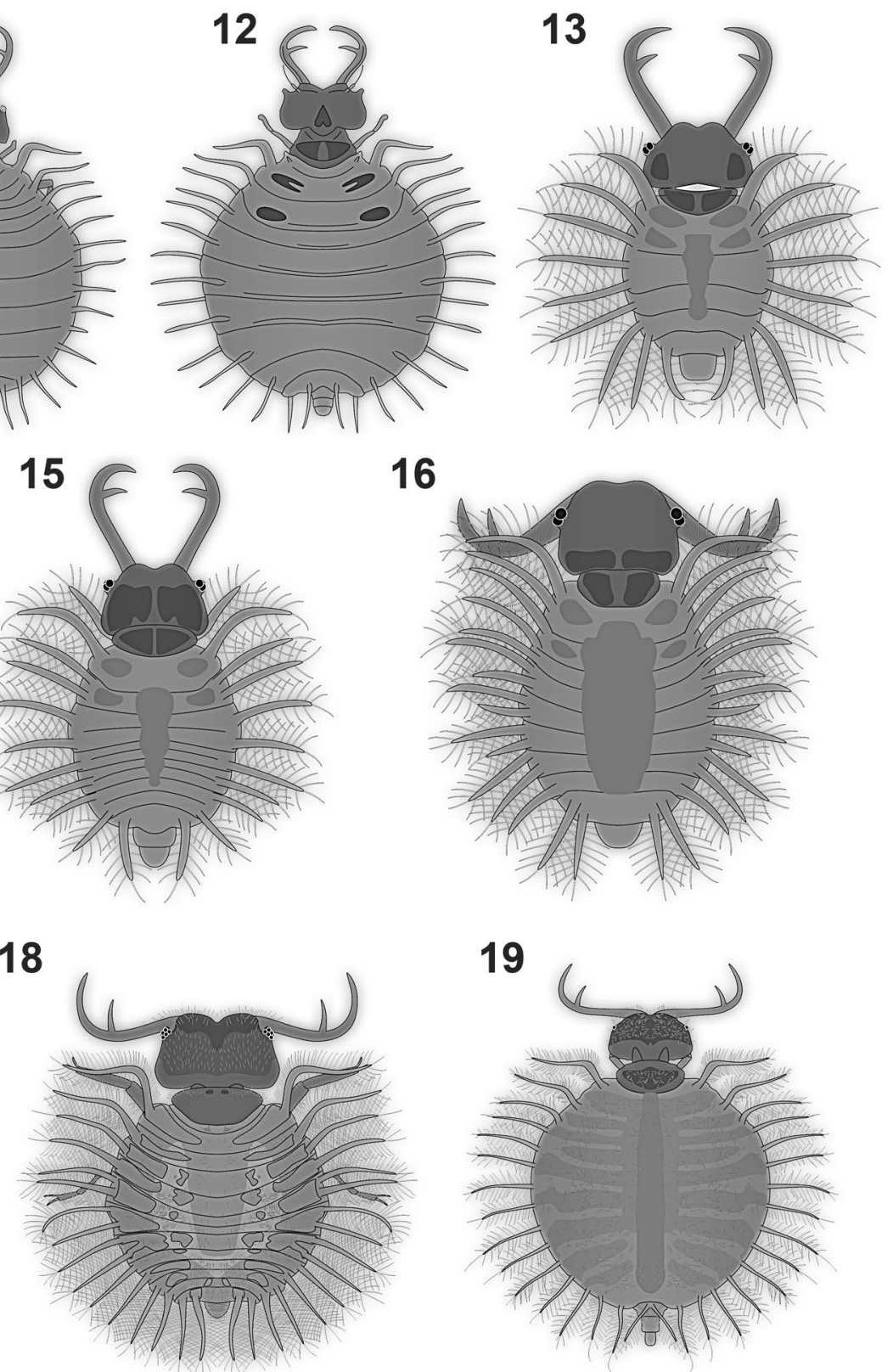

16
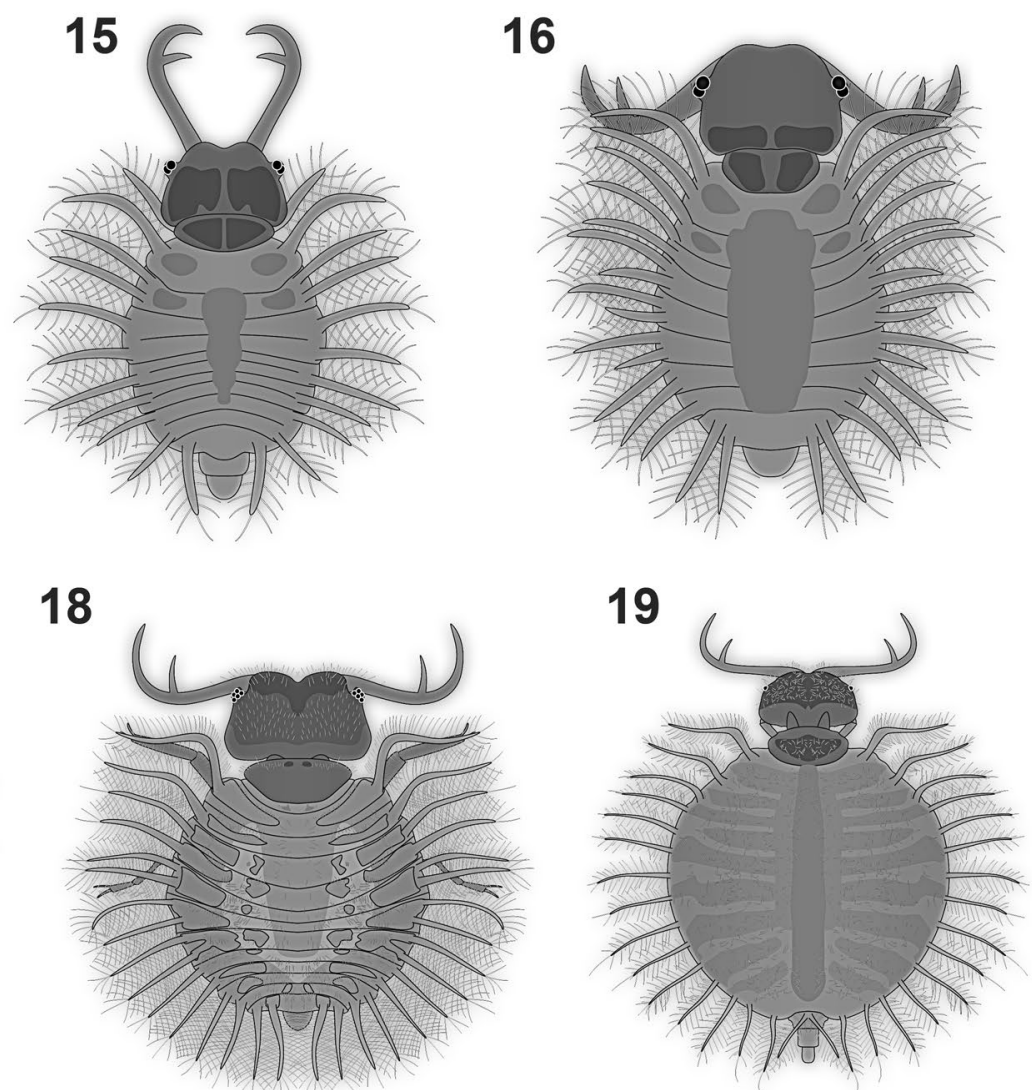

Fig. 1 (continued)

According to figure captions, the image was originally provided by Simon Grove.

Websites - are generally not considered to be reliable scientific sources. Yet, given the scarcity of data on larvae of Nymphidae, we decided to use certain online repositories as additional data sources (e.g. see Haug and Haug 2019). The database "Atlas of Living Australia" (https://ala.org. au) provides individual identifiers for each specimen and with this facilitates a clear specimen identification. In total, eight specimens from this database, all documented as photographs, are considered here:
The first specimen has the catalogue number iNaturalist Australia 32152668 (specimen 19; Fig. 1). This specimen was provisionally identified on the website as a larva of a species of Myiodactylus. The photograph was provided by Lily Kumpe.

The second specimen has the catalogue number iNaturalist Australia 27397806 (specimen 20; Fig. 1). This specimen was provisionally identified on the website as a larva of a species of Osmylops. The photograph was provided by Daniel Hobern. 

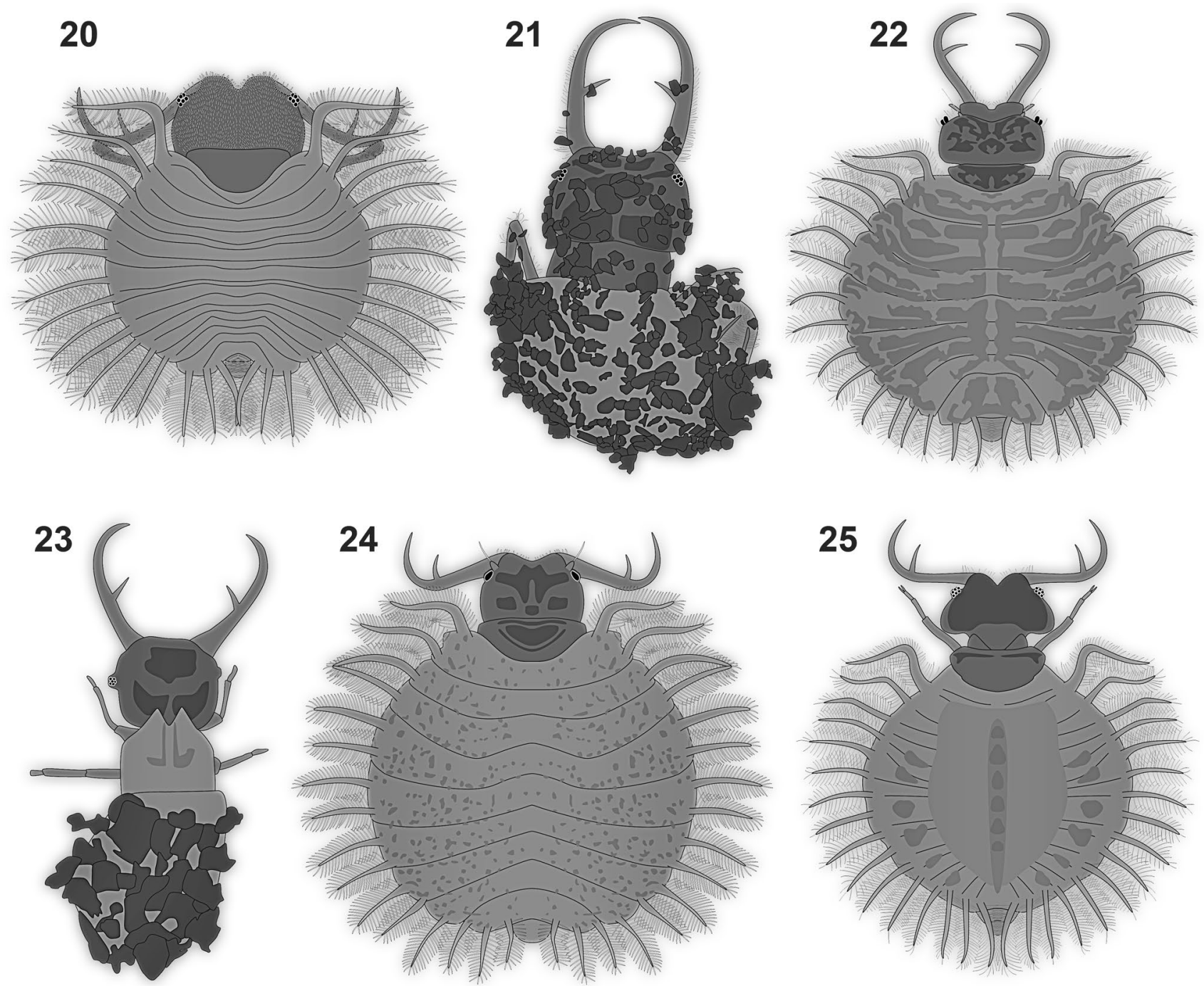

Fig. 1 (continued)

The third specimen has the catalogue number iNaturalist Australia 34194103 (specimen 21; Fig. 1). The specimen was provisionally identified on the website as a larva of Nymphidae. Photograph was provided by Martin M. Lagerwey.

The fourth specimen has the catalogue number bowerbird 100717 (specimen 22; Fig. 1). The specimen was provisionally identified on the website as a larva of Nymphidae. The photograph was provided by Mike M. Ford.

The fifth specimen has the catalogue number iNaturalist Australia 9714736. The specimen was provisionally identified on the website as a larva of Nymphidae. The photograph, provided by Simon Grove, is the one depicted in Badano et al. (2017), hence specimen 18 (Fig. 1). The image deposited in the database is of higher resolution and was therefore used by us for redrawing it.
The sixth specimen has the catalogue number bowerbird 41396 (specimen 23; Fig. 1). This specimen was provisionally identified on the website as a larva of Nymphidae. The photograph was provided by Rosie R. Benz.

The seventh specimen has the catalogue number iNaturalist Australia 37327165 (specimen 24; Fig. 1). The specimen was provisionally identified on the website as a larva of a species of Osmylops. The photograph was provided by Glenda G. Walter.

The eighth specimen has the catalogue number iNaturalist Australia 27688249 (specimen 25; Fig. 1). The specimen was provisionally identified on the website as a larva of Nymphidae. The photograph was provided by Martin M. Lagerwey. 

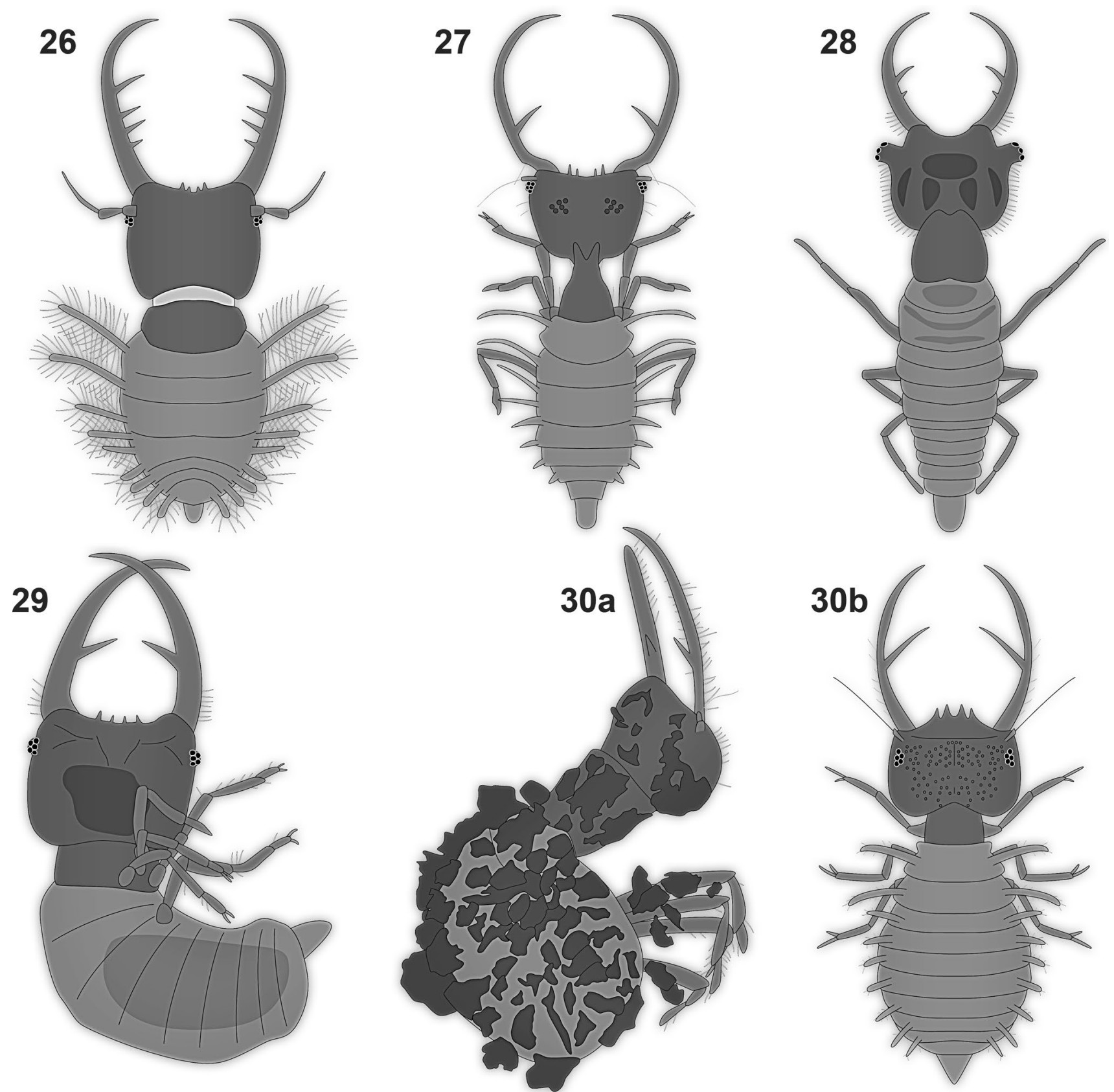

Fig. 1 (continued)

\section{Fossil larval forms resembling those of Nymphidae, depicted in the literature}

As for extant forms, all occurrences of depictions are listed chronologically. Cases in which the same specimen has been re-figured are also included chronologically with reference given to the original occurrence.

Weidner (1958) - apparently figured a larva in Eocene Baltic amber originally interpreted as a representative of Ascalaphidae (specimen 26; Fig. 1). We could not access this publication, but later publications have re-figured the specimen (MacLeod 1970). The specimen was later reinterpreted as larva of the group Nymphidae (see next point).

MacLeod (1970) - re-figured specimen 26 (the one from Weidner 1958). He suggested it to represent the larva of Pronymphes mengeanus (MacLeod 1970: 158). Images include a simplified drawing of the left body half in dorsal view (p. 156, fig. 5), and two photographs, one of the entire specimens in dorsal view (p. 160, fig. 6), the second is a closeup of the mandible teeth (p. 162, fig. 7). MacLeod (1970) 
suggested that the specimen represents a stage 1 larva ( $\mathrm{p}$. 163). According to the provided scale, the specimen has an overall body length of $2.44 \mathrm{~mm}$.

Xia et al. (2015)_provided photographs of two larval specimens of interest in Cretaceous Myanmar amber. The first (p. 98, lower right) has one single, prominent tooth per mandible and was later (see further below) interpreted as a larva of Nymphidae (specimen 27; Fig. 1). Another prominent feature is a group of four prominently noticeable spines on the anterior rim of the head. The specimen was re-figured in Wang et al. (2016) and Badano et al. (2018). According to the provided scale (by Badano et al. 2018), the specimen has an overall body length of $3.72 \mathrm{~mm}$.

The second specimen (p. 98, lower left) has one larger tooth and, further proximally, another much smaller tooth. While most larval representatives of Nymphidae have a single tooth in the mandible, MacLeod (1970: 165) has pointed out that this condition has been variable throughout the lineage. We will therefore include the specimen for further consideration (specimen 28; Fig. 1).

Wang et al. (2016)-provided images of two larval specimens in Cretaceous Myanmar amber with one tooth per mandible. These were categorised as morphotype M1. A simplified restoration drawing of morphotype M1 (p. 6, fig. 6) is most likely based on the two specimens and therefore not further considered here to avoid duplication.

The first specimen is seen in oblique ventral view (their suppl-fig. 3f) and is similar to specimen 27 in having four prominent spines on the anterior rim of the head (specimen 29; Fig. 1). The accession number is NIGP 164051. The specimen has an overall body length of $4.4 \mathrm{~mm}$, according to the provided scale.

Wang et al. (2016) also re-figured specimen 27 (p. 4, fig. 3a), i.e. one specimen from Xia et al. (2015). The accession number was given as BA12015. Additionally, a closeup photograph of the head region is provided (their supplfig. 2d; erroneously labelled as "Morphotype M II [...]").

Badano et al. (2018)_provided images of two larval specimens in Cretaceous Myanmar amber with one tooth per mandible. They also erected the species Nymphavus progenitor for these and three further specimens.

The first specimen (specimen 30; Fig. 1: 30a) was shown in lateral view (p. 5, fig. 3c). The accession number is AMNH JCZ-Bu33A; it was designated as a paratype. Additionally, there is a close-up of the head region in dorsal view (suppl. figure 2a erroneously labelled as "[...] holotype AMNH JCZ-Bu30 [...]"). It is not possible to see whether the specimen also has the four prominent spines on the anterior rim of the head as this region is covered with detritus. The posture of the specimen does not allow to estimate the overall length, the head length according to scale is $0.97 \mathrm{~mm}$.
The second specimen (their suppl. fig. 1h) is specimen 27, i.e. BA12015. It was designated as the holotype. The image was erroneously labelled as "Pristinofossor rictus gen. et sp. nov., holotype AMNH JCZ-Bu304, detail of mandible”.

Three additional specimens are mentioned as paratypes, but were not figured. Specimen with accession number NIGP 164051 appears to refer to specimen 29, i.e. one of the specimens figured in Wang et al. (2016). The other two mentioned specimens have the accession numbers NIGP 164047 and NIGP 164058. These two specimens seem to have never been figured, also not in other occasions. A restoration drawing for the larval morphology of the species Nymphavus progenitor was also presented (p. 10, fig. 4(iv); simplified in Fig. 1: 30b).

Furthermore, there is another specimen figured that has one tooth per mandible. Yet, this tooth has two tips and is quite massive. According to the phylogenetic analysis (Badano et al. 2018: 10, fig. 4), the species represented by this specimen is not an in-group of Nymphidae. Instead, it appears to be much closer related to the larger group including Ascalaphidae and Myrmeleontidae. The specimen is therefore not further considered here.

Hörnig et al. (2020)—provided images of a larval specimen in Cretaceous Myanmar amber with one tooth per mandible (specimen 31; Fig. 2). The specimen is re-figured here as photographic images as well. The original accession number is SNSB-BSPG 2020 XCIII 18. The specimen differs from larvae of Nymphavus progenitor by the shape of the mandible. It remains unclear whether the specimen also possesses the four prominent spines on the anterior rim of the head or not. According to the provided scale, the specimen has an overall body length of $2.26 \mathrm{~mm}$.

\section{New fossil larval forms resembling those of Nymphidae}

All specimens listed below are preserved in Cretaceous Myanmar amber.

Specimen 32-is heavily covered by debris (Fig. 3a-d). Therefore, most details are not accessible. Its original accession number was BUB 3382a. The specimen has an overall body length of $2.53 \mathrm{~mm}$.

Specimen 33-is likewise covered by debris, but less so than the preceding specimen (Fig. $3 \mathrm{e}-\mathrm{g}$ ). It has a mandible shape resembling that of specimen 31 . The accession number is PED 0532. The specimen has an overall body length of $1.61 \mathrm{~mm}$.

There are three additional specimens-resembling those that have been described as Nymphavus progenitor. This is well apparent by the characteristic, prominent spines on the anterior rim of the head. Accession numbers of these specimens are PED 0377 (specimen 34; Fig. 4), PED 0579 


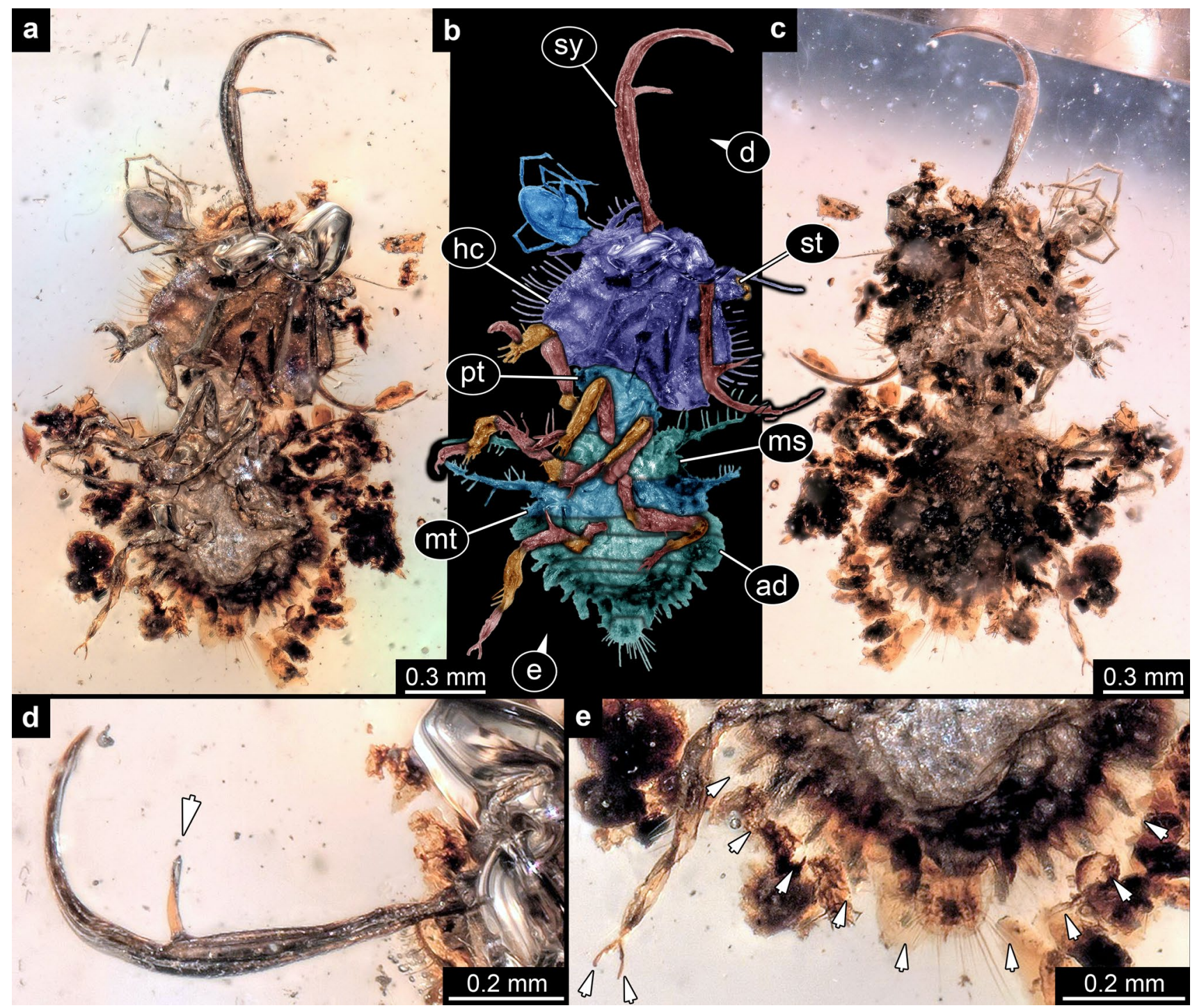

Fig. 2 Larva of Nymphidae in Myanmar amber, specimen 31 (SNSBBSPG 2020 XCIII 18); all images under ring light, with white background. a Ventral view. b Same as a, but colour-marked. c Dorsal view. d Close-up of stylet; arrow indicates the single tooth. e Close-

(specimen 35; Fig. 5a-c), and PED 0665 (specimen 36; Fig. $5 \mathrm{~d}-\mathrm{g}$ ). Specimen 34 has an overall body length of $2.74 \mathrm{~mm}$. Specimen 35 cannot be measured exactly due to its oblique and twisted posture, yet it may have measured about $3.5 \mathrm{~mm}$. Specimen 36 is incomplete as the posterior trunk is missing; its head length is about $1.03 \mathrm{~mm}$.

Two rather large specimens - resemble each other. Both are rather incomplete, the cuticle pieces often show gaps between them. PED 0458 (specimen 37; Fig. 6f, g) has only the head preserved with the stylets. The head length of specimen 37 is $1.68 \mathrm{~mm}$. PED 0474 (specimen 38; Fig. 6a-e) has the head preserved isolated from the body. The body appears somewhat crumpled, yet the details of the trunk appendages are accessible. The crumpled condition indicates that this is up of distal region of protrusions on trunk in ventral view and a thorax appendage (leg); arrows indicate protrusions and claws. ad abdomen, $h c$ head capsule, $m s$ mesothorax, $m t$ metathorax, $p t$ prothorax, $s t$ stemmata, sy stylet

an exuvium. Specimen 38 is difficult to measure accurately, but can be estimated to have a length of about $8.5 \mathrm{~mm}$.

BUB 0797 (specimen 39; Fig. 7) -is very well preserved. The trunk is rather slender; trunk segments bear short processes. The specimen has an overall body length of $4.16 \mathrm{~mm}$.

PED 0423 (specimen 40; Fig. 8)—resembles specimen 28 in having one large and one small tooth per mandible. The posterior trunk end is not well visible, yet the specimen has an estimated overall body length of $8 \mathrm{~mm}$.

\section{Shape analysis}

In total, 25 extant specimens of larvae of Nymphidae were available. Of these, 21 can be included in the shape analysis 
(Fig. 9). In the four specimens that could not be included, the mandibles are in locked position: the mandibles are swung back far so that the proximal region of the mandible is concealed by parts of the head capsule.

In total, there are 15 fossil specimens of neuropteran larvae that have either already been interpreted as representatives of Nymphidae, or resemble them in having a single large tooth in the mandible. This also includes larvae with one large and one smaller tooth, or with one large and three smaller teeth. Of these 15 , only 13 can be included into the shape analysis (Fig. 10). Specimens that could not be considered for the shape analysis are those that are embedded in an oblique angle (PED 0579, BUB 0797).

The analysis was performed with 20 harmonics. This resulted in 74 principal components; eight of these are effective principal components (Fig. 11, suppl. figure 1, suppl. text 1$)$.

PC1 explains $51.17 \%$ of the overall variation. It is strongly influenced by the relative width of the head and the relative position of the single tooth in the mandible. A lower value indicates a more slender head and a more proximal position of the tooth. A higher value indicates a wider head and a more distal position of the tooth.

PC2 explains $15.31 \%$ of the overall variation. Also, here the relative width of the head has a strong influence and furthermore the curvature of the mandible. A lower value indicates a more slender head and a straighter mandible. A higher value indicates a wider head and a distally strongly curved mandible.

PC1 and PC2 combined explain already $66.48 \%$ of the overall variation. While we have seen already higher values in other analyses (e.g. Haug et al. 2020), this value is still acceptable. PC1 and PC2 are used for most of the plots, in one plot all eight effective PCs are shown.

PC3 explains $9.10 \%$ of the overall variation. It is strongly influenced by the shape of the posterior region of the head and the position of the single tooth. A lower value indicates the presence of protruding posterior corners of the head (temples) and a more distal position of the tooth. A higher value indicates straight posterior corners of the head and a more proximal position of the tooth.

PC4 explains $6.35 \%$ of the overall variation. It is strongly influenced by the position of the single tooth and the length of this tooth. A lower value indicates a distal position of the tooth and a rather short tooth. A higher value indicates a more proximal position of the tooth and a rather long tooth.

PC5 explains $3.80 \%$ of the overall variation. It is strongly influenced by the thickness of the mandible and the shape of the posterior region of the head. A lower value indicates a proximally rather thin mandible and a slightly concave posterior edge of the head. A higher value indicates a proximally broader mandible and a slightly convex posterior edge of the head.

PC6 explains $3.28 \%$ of the overall variation. It is strongly influenced by the thickness of the mandible and the relative width of the head. A lower value indicates distally thick mandibles and a wider head. A higher value indicates a distally thin mandible and a narrower head.

PC7 explains $2.47 \%$ of the overall variation. It is strongly influenced by the shape of the mandible. A lower value indicates a broader mandible and a short tooth. A higher value indicates a thin mandible and a longer tooth.

PC8 explains $1.95 \%$ of the overall variation. It is strongly influenced by the shape of the mandible. A lower value indicates a thinner and straighter mandible. A higher value indicates a broader and more curved mandible.

Plotting PC1 and PC2 against head lengths (where available) reveals no recognisable correlation between length and shape of the head (PC1: $R^{2}=0.06$; PC2: $R^{2}=0.005 ;$ Fig. 12).

\section{Discussion}

\section{The general challenge: nobody cares for larvae}

We were able to compile a mere 25 extant larvae of splitfooted lacewings, including five individuals from a single photograph, as well as seven specimens from citizen science databases. The degree of details available is sometimes quite low. This is also reflected by a statement from MacLeod (1970): "The few known larvae [...] of Nymphidae have been poorly described" (p. 163). While some significant additions have been made since this statement (New 1982, 1983; New and Lambkin 1989), the overall situation is still unsatisfying.

Having only such a low number of larvae available is, unfortunately, a general pattern (e.g. Haug and Haug 2019; Haug et al. 2020). This overall apparent ignorance against larvae is not easy to understand. Many species of the group Holometabola spend the larger part of their life time as larvae, whereby many individuals will not make it into adulthood. This makes it easily apparent that larvae are, in fact, the more important part of the life phases from an ecological standpoint, interacting more with their environment than the adults.

The fossil record actually provides us a good access to larval forms. Yet, the lack of biological knowledge regarding extant forms necessarily limits the palaeobiological aspects that can be inferred from fossil forms. This leads to a further, even more expressed, ignorance against fossil larvae.

Despite this ignorance, the astonishing morphologies of many of the fossil larvae indicate quite a variety of ecological functions (e.g. Pérez-de la Fuente et al. 2012, 2016, 


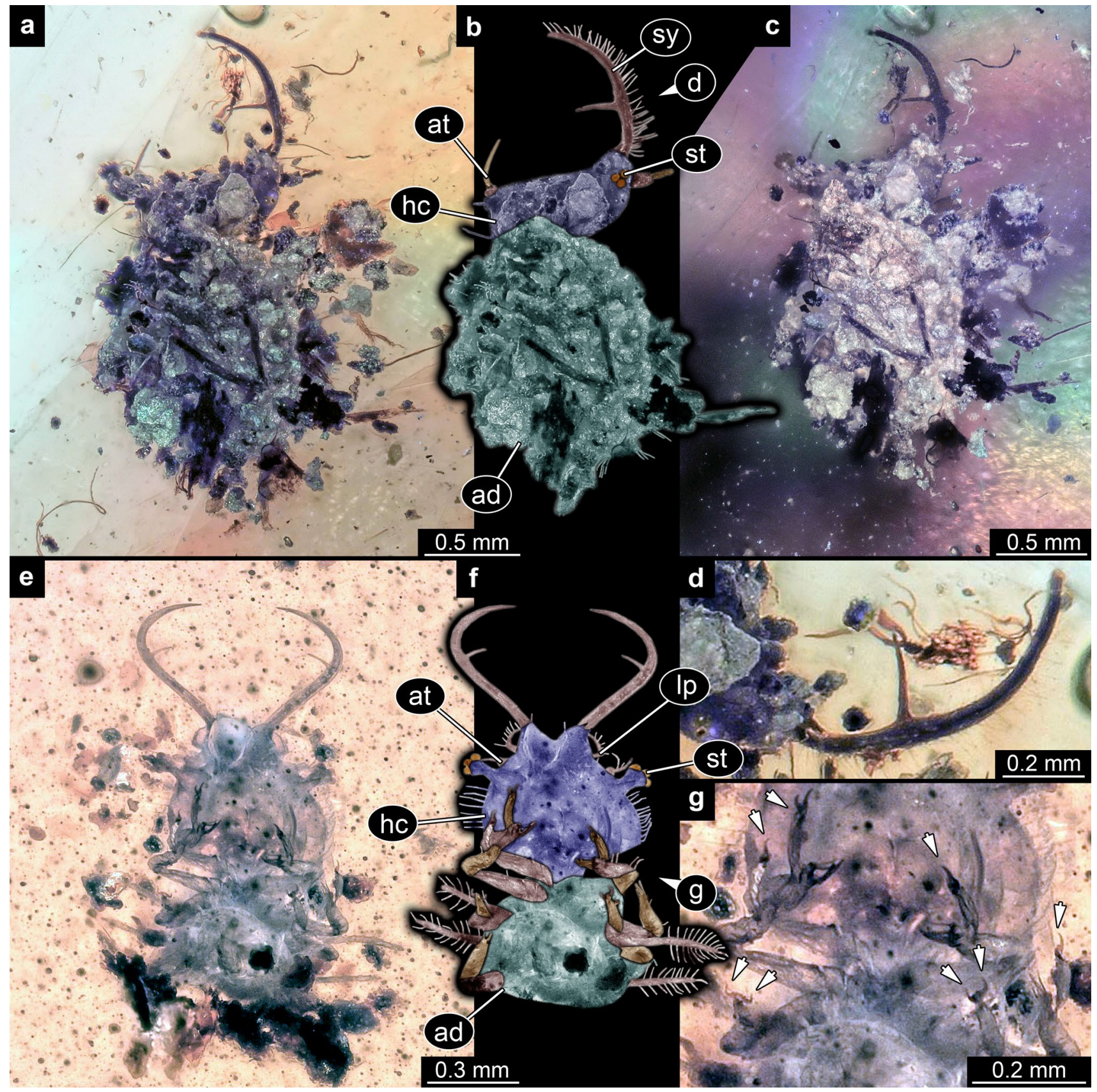

Fig. 3 Larvae of Nymphidae in Myanmar amber. a-d Specimen 32 (BUB 3382); all images under cross-polarised light. a Dorsal view, white background. b Same as a, but colour-marked. c Dorsal view, black background. d Close-up of mandible. e-g Specimen 33 (PED

2018, 2019, 2020; Wang et al. 2016; Liu et al. 2016, 2018; Badano et al. 2018; Haug et al. 2019a, b, c) that have been fulfilled by these larvae in the past. We therefore emphasise that both fossil and extant larvae provide significant insights, also for example for inferring diversity, which will be further explored in detail.
0532); all images under ring light. e Ventral view, white background. f Same as e, but colour-marked. g Close-up of thorax appendages (legs); arrows indicate claws. $a d$ abdomen, at antenna, $h c$ head capsule, $l p$ labial palp, st stemmata, sy stylet

\section{Are the fossils larvae of the group Nymphidae?}

As a first step, we need to evaluate whether the fossils discussed here are indeed larval forms of the group Nymphidae. Many larval forms of Myrmeleontiformia bear teeth in their mandibles (see discussion in Haug et al. 2019a). 


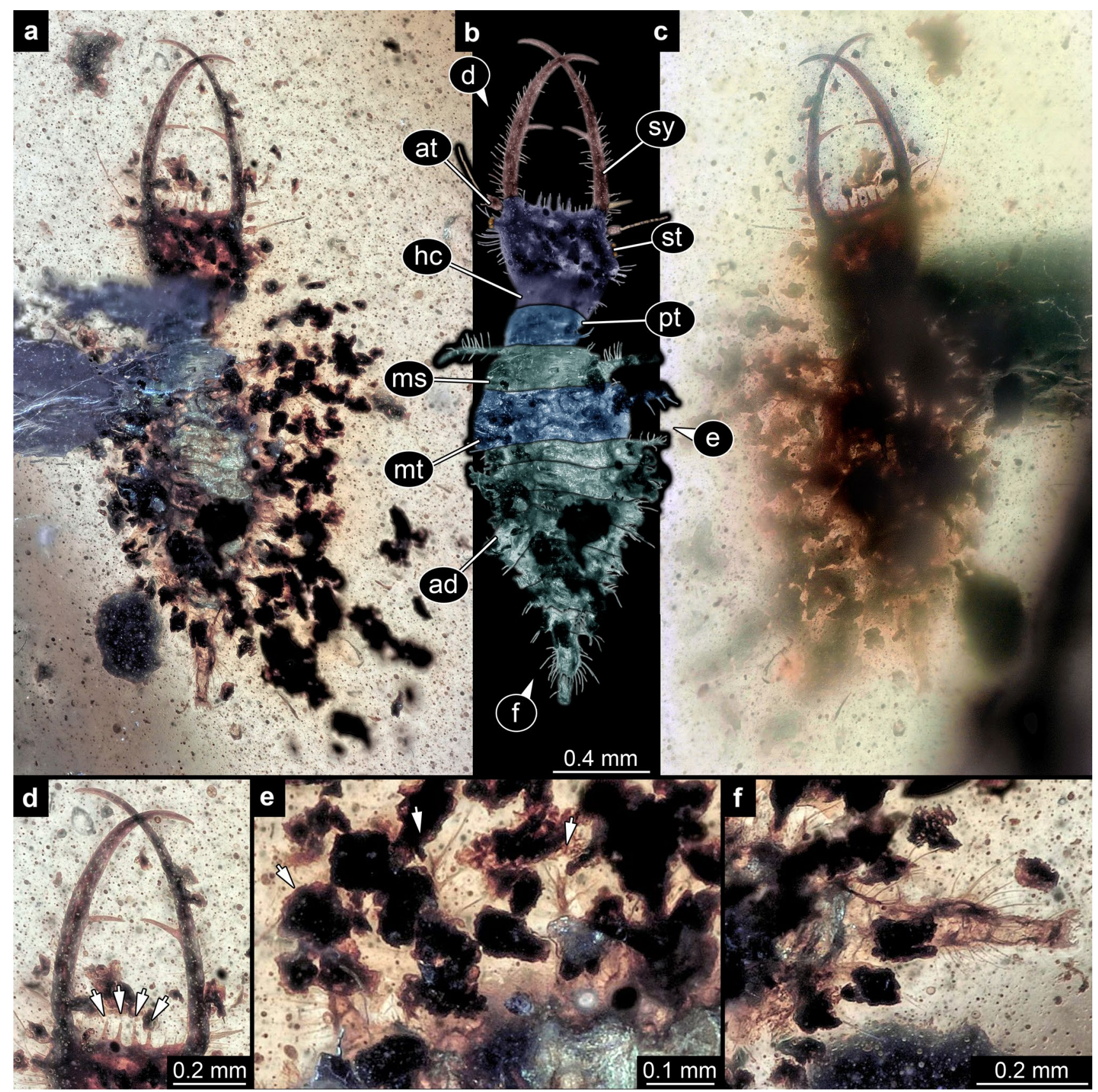

Fig. 4 Larva of Nymphidae in Myanmar amber, specimen 34 (PED 0377). a Dorsal view, white background; image under ring light. b Same as a, but colour-marked. c Ventral view, white background; image under transmitted light. d Close-up of mandibles in dorsal view; arrows indicate protrusions on anterior rim of head capsule.

Many larvae of Ascalaphidae (the group of owlflies) and Myrmeleontidae (antlions) have three such teeth. Yet, some extant larvae of Myrmeleontidae have between one and four teeth per mandible (MacLeod 1964, 1970). Owlflylarva-like fossils of an offshoot of the lineage before the split of Ascalaphidae and Myrmeleontidae have two teeth e Close-up of distal region of protrusions on trunk in dorsal view; arrows indicate protrusions. f Close-up of the trunk end in dorsal view. ad abdomen, at antenna, $h c$ head capsule, $m s$ mesothorax, $m t$ metathorax, $p t$ prothorax, st stemmata, sy stylet

(Badano et al. 2018). Yet, a single and prominent tooth in each mandible seems indeed restricted to larvae of Nymphidae. Also, larvae of Myrmeleontidae and Ascalaphidae have a continuous ("fused") tibio-tarsus (MacLeod 1970: 164), while in all fossils in which the trunk appendages (legs) are apparent, the tarsus is set off from the tibia. Therefore, these 


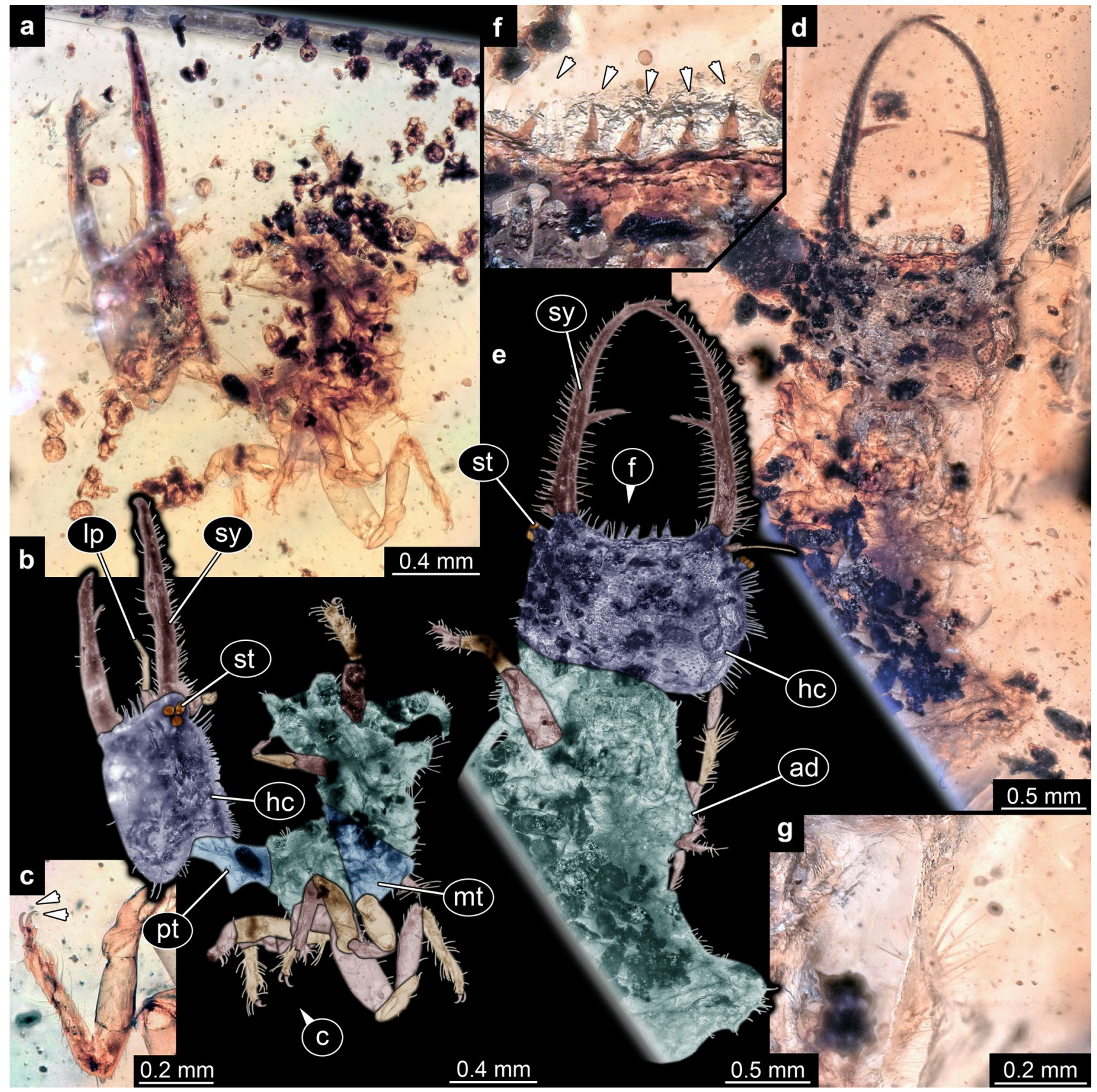

Fig. 5 Larvae of Nymphidae in Myanmar amber. Specimen 35 (PED 0579); all images under cross-polarised light, with white background. a Oblique view. b Same as a, but colour-marked. c Close-up of thorax appendage (leg); arrows indicate claws. d-g Specimen 36 (PED 0665); all images under ring light, with white background. d Dorsal

morphological characters indicate that all larvae discussed here are possible larvae of the group Nymphidae.

The single fossil larva from the Eocene (specimen 26; Fig. 10) has been interpreted as an early representative of Nymphidae by MacLeod (1970). This interpretation was supported by the phylogenetic analysis of Badano et al. (2018: 10, fig. 4). We therefore follow this interpretation. view. e Same as $\mathbf{d}$, but colour-marked. f Close-up of protrusions at the anterior rim of the head capsule; arrows indicate protrusions. $\mathrm{g}$ Close-up of thorax appendages (legs). ad abdomen, $h c$ head capsule, $l p$ labial palp, $m t$ metathorax, pt prothorax, st stemmata, sy stylet

Eight of the larvae from Myanmar amber plot quite close together when plotting PC1 and PC2 (Fig. 10). Among these are several specimens that are clearly representatives of the species Nymphavus progenitor. This species was likewise resolved as a deeper in-group of Nymphidae by Badano et al. (2018). We also follow this interpretation. One of the larvae that could not be included 


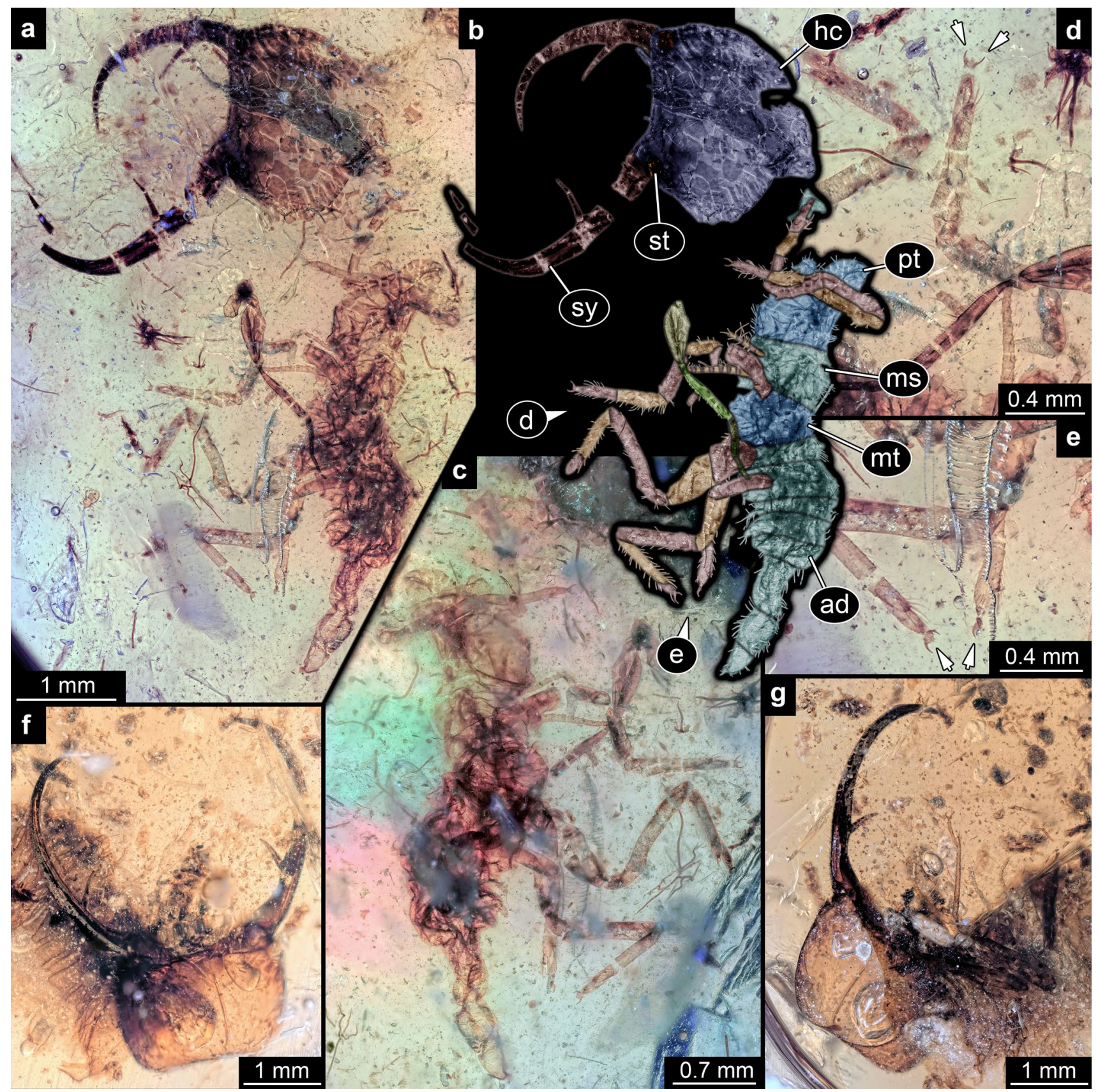

Fig. 6 Larvae of Nymphidae in Myanmar amber. a-e Specimen 38 (PED 0474); all images under cross-polarised light, with white background. a Oblique or dorso-lateral view. b Same as a, but colour-marked. c Oblique or ventro-lateral view. d Close-up of thorax appendages (legs); arrows indicate claws. e Close-up of thorax

in the shape analysis (specimen 35) strongly resembles Nymphavus progenitor and is therefore likewise interpreted as a larva of the same type.

Specimens 31 and 33 differ from the Nymphavus-type larvae (Fig. 10). The mandibles of these two larvae are in fact more similar to those of certain modern larvae of Nymphidae, those of Myiodactylinae, in being proximally straight appendages (legs); arrows indicate claws. f-g Specimen 37 (PED 0458); all images under ring light, with white background. f Dorsal view (?). g Ventral view (?). ad abdomen, $h c$ head capsule, $m s$ mesothorax, $m t$ metathorax, $p t$ prothorax, st stemmata, sy stylet

and curved distally, and having the single tooth sitting quite far distally. As this mandible morphology appears to be a derived condition, we consider these larvae as closer related to, or even in-group representatives of, Myiodactylinae. We therefore also consider these two larvae as clear representatives of Nymphidae. 


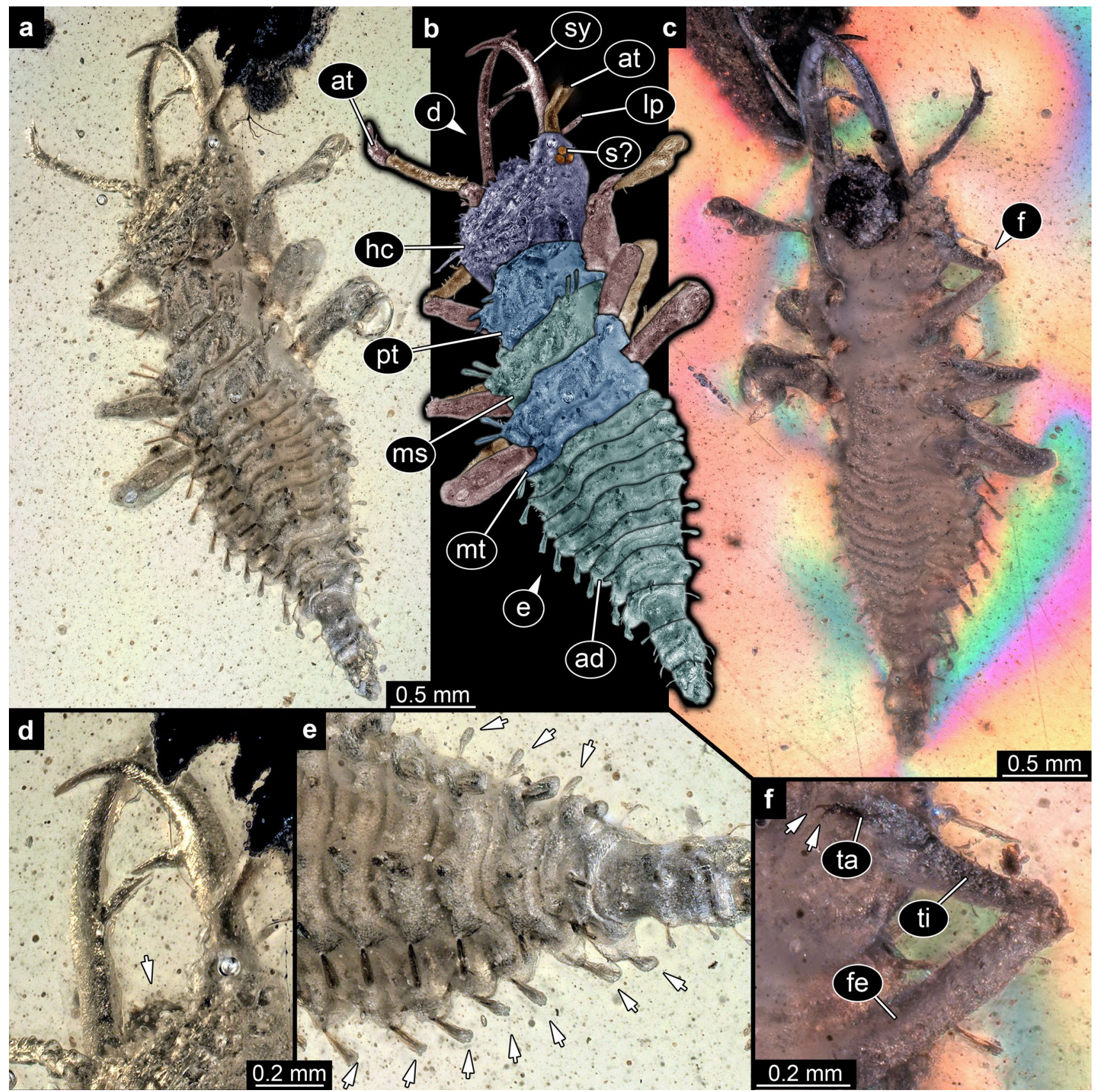

Fig. 7 Larva of Nymphidae in Myanmar amber, specimen 39 (BUB 0797). a Dorsal view, under ring light, with white background. b Same as a, but colour-marked. c Ventral view, under cross-polarised light, with black background. d Close-up of protrusion and stylets at the front of the head capsule; arrow indicates protrusion. e Close- up of distal region of protrusions on trunk in dorsal view; arrows indicate protrusions. f Close-up of thorax appendage (leg); arrows indicate claws. ad abdomen, at antenna, $f e$ femur, $h c$ head capsule, $l p$ labial palp, $m s$ mesothorax, $m t$ metathorax, $p t$ prothorax, $s$ ? stemmata?, sy stylet, $t a$ tarsus, $t i$ tibia
Specimens 28 and 40 possess one large and one small tooth per mandible (Fig. 10). The presence of a smaller tooth is no direct exclusion argument, as demonstrated by the discussion in MacLeod (1970) and the specimen from the Eocene (see above). One could argue that the two specimens resemble owlfly-larvae-like forms (more precisely, larvae of species that are offshoots of the direct lineage before the split of Ascalaphidae + Myrmeleontidae, according to Badano et al. 2018: 10, fig. 4). Yet, the position of the teeth on the mandible is in fact different from the owlfly-larva-like forms. In the owlfly-larva-like forms, there are two teeth per mandible, which are even sized. Their position rather 


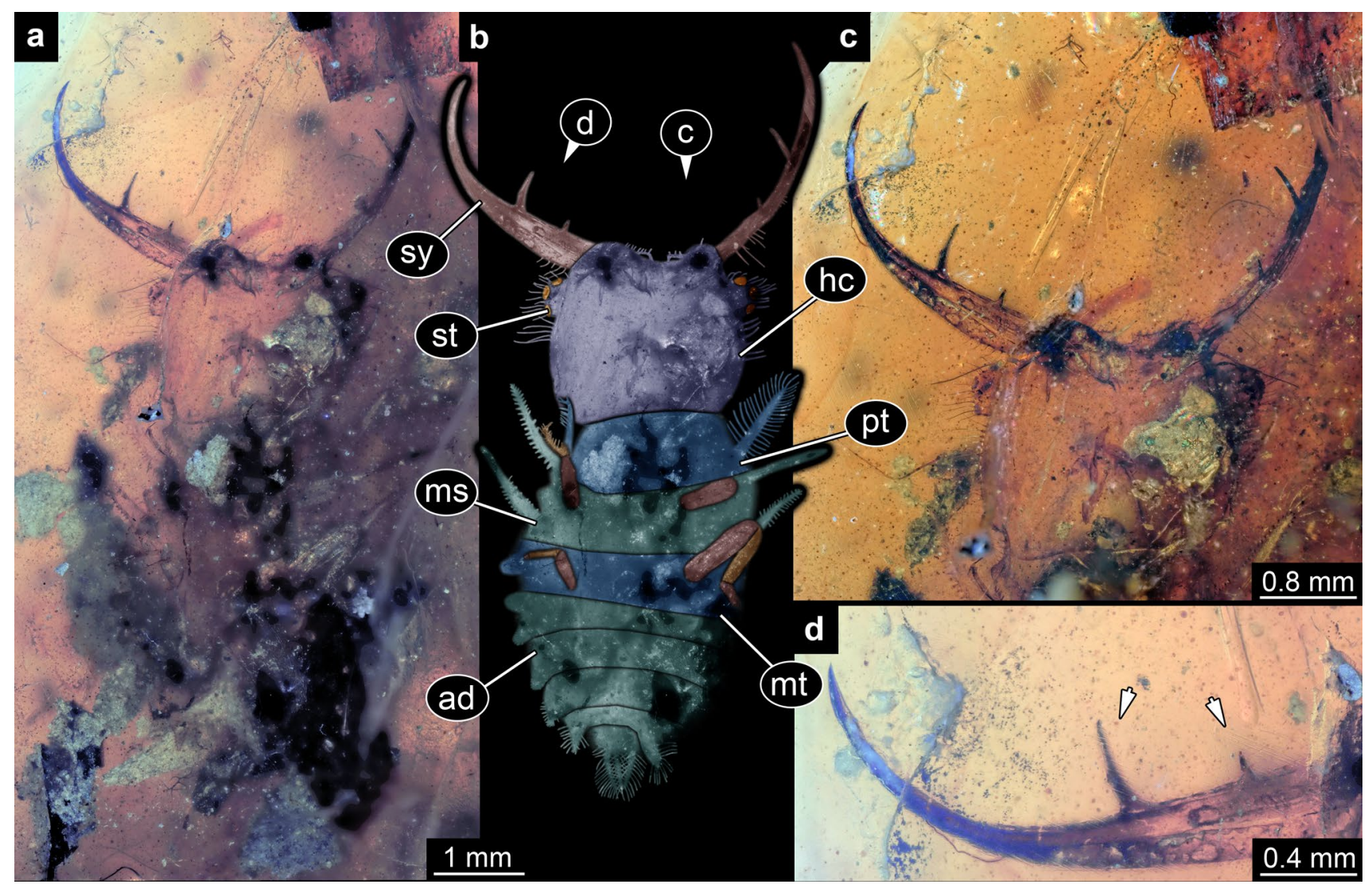

Fig. 8 Larva of Nymphidae in Myanmar amber, specimen 40 (PED 0423). a Ventral view (?), under cross-polarised light, with white background. b Same as a, but colour-marked. c Close-up of head cap- sule under ring light. d Close-up of stylet; arrows indicate the teeth. $a d$ abdomen, $h c$ head capsule, $m s$ mesothorax, $m t$ metathorax, $p t$ prothorax, st stemmata, sy stylet evenly divides that mandible into three thirds (e.g. Wang et al. 2016; fig. 3b, c; Fig. 6; Badano et al. 2018; fig. 3e, f; fig. 4vi). This is different in the two specimens with one large and one smaller tooth per mandible: the larger tooth sits at about half way along the proximal distal axis. The smaller tooth sits further proximally. We therefore consider the two larvae as possible representatives of Nymphidae, or at least as closely related to this lineage.

Finally, the other larva that could not be included in the shape analysis (specimen 39) differs from the other fossil larvae especially in the relatively slender trunk. Usually, only stage 1 larvae possess a more slender trunk. This might indicate that it is a stage 1 larvae; such larvae can be more slender than later ones (e.g. New 1982). Yet, for a stage 1 larva, it is relatively large, but this possibility cannot be excluded. Hence, also here all available characters are compatible with an interpretation of this larva as a representative of Nymphidae.

\section{Differentiation of extant forms}

Traditionally, two types of larvae within Nymphidae are differentiated, the so-called myiodactlid type (larvae of Myiodactylinae) and the myrmeleontid type (larvae of Nymphinae) (Shi et al. 2015). The latter type is most likely named as such due to the similarity of larvae of this type to the larval form of Myrmeleontidae. This mostly accounts for the shape of the trunk, which is more slender. Yet, this does not really mean slender in an absolute way (compare for example against specimens in Haug et al. 2019a, c), but it means longer than wide. This type of morphology is most likely a plesiomorphic trait. Myiodactylid-type larvae have a wider trunk that is almost circular, and in some cases even wider than long, at least in the later larval stages. Earlier larvae are not yet that wide.

However, there are many other differences. Myrmeleontid-type larvae lack prominent processes on the trunk; myiodactylid-type larvae have quite prominent processes, even in early larval stages. The head shape is also different; myrmeleontid-type larvae have roughly square-shaped heads; the heads of myiodactylid-type larvae are wider. 
Fig. 9 Shape analysis of the heads of larval specimens of Nymphidae. Yellow squares represent the extant specimens, blue diamonds represent fossil specimens. The extant specimen head and mandible morphologies are depicted around the plot

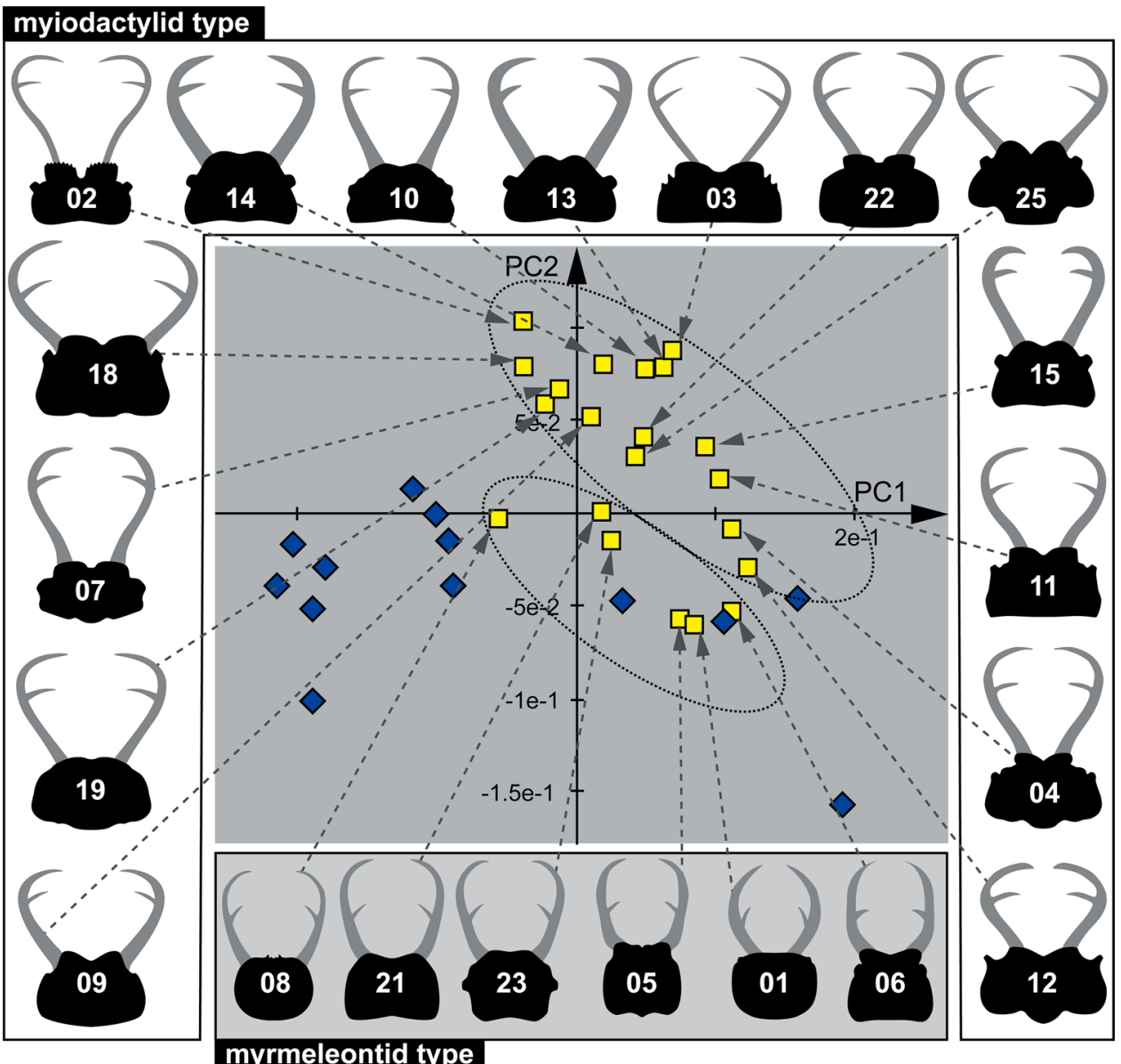

Also, the mandibles are different between the two types. Myrmeleontid-type larvae have simply curved mandibles with the single tooth sitting almost in the middle along the proximal-distal axis. In myiodactylid-type larvae, the mandibles are proximally straight or even slightly outward curved and then distally sharply curved inward. The single tooth sits further distally.

Due to the differences in head shape and mandible shape, the basic differentiation into two types can also be recognised in the shape analysis. There is no strong separation. Some specimens traditionally interpreted as myiodactylid-type larvae plot closer to some myrmeleontidtype larvae than some other specimens of the same type (specimen 6 plots closer to 12 than to 8; Fig. 9). While there is not a lot of distance between the two groups, there is also no intermixing. Hence, the method applied here works well to also recognise such classical groups.

\section{Differentiation of fossil forms}

The fossil forms can be roughly differentiated into four types. The single specimen from the Eocene (specimen
26) plots separately from all other specimens and clearly represents a type on its own. A second type is represented by two more or less distinct, smaller clusters of four specimens each. In both of these clusters, at least one specimen bears prominent forward oriented spines or strong setae (mostly four) as those known for larvae of the species Nymphavus progenitor. We therefore recognise all these as a single type. It cannot be excluded that this type includes several species; therefore, we remain careful and do refer to them together as a type instead of a species. Specimens 40 and 28 differ from all other larvae in possessing one large and one small tooth per mandible. They separate well from the Nymphavus-type larvae. Yet, they plot closer to specimen 31. Specimen 33 plots further away. Both specimens have mandibles resembling those of extant myiodactylid-type larvae. Yet, the heads of both larvae are not significantly wider as it would be typical for extant myiodactylid-type larvae. The head shape, especially in specimen 31, resembles that of the larvae more, with one large and one small tooth per mandible. 
Fig. 10 Shape analysis of the heads of larval specimens of Nymphidae, continued. Yellow squares represent the extant specimens, blue diamonds represent fossil specimens. The fossil specimen head and mandible morphologies are depicted around the plot

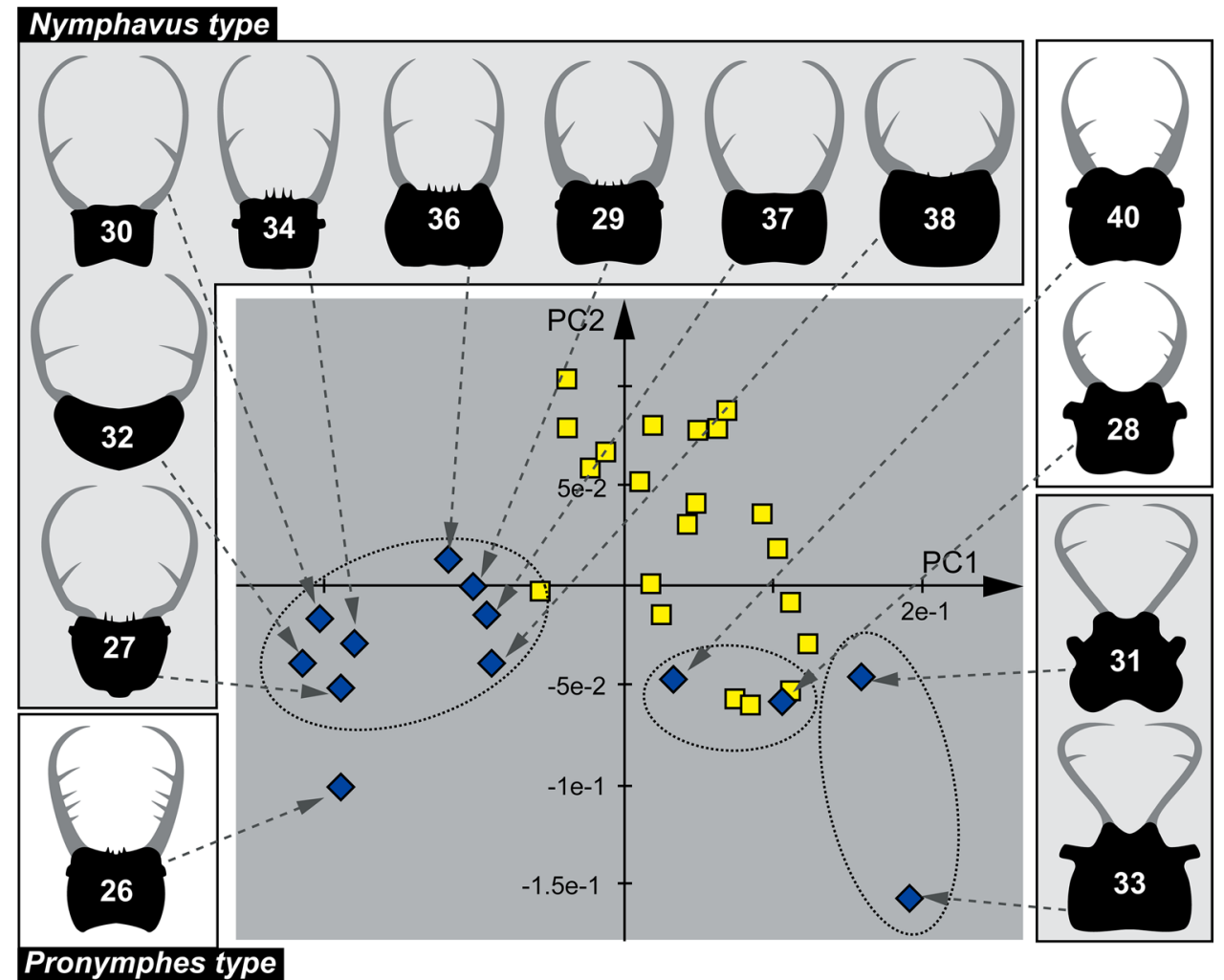

\section{Differentiation of fossil from extant forms}

At first sight, one might get the impression that Nymphavus-type larvae roughly resemble modern myrmeleontidtype larvae and that the type represented by specimens 31

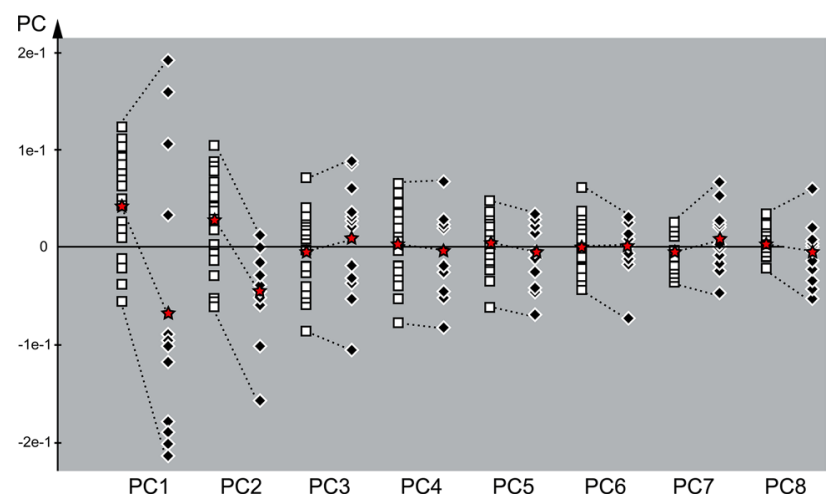

Fig. 11 Range of the eight effective principal components of the shape analysis of larvae of Nymphidae. White squares represent the extant specimens, black diamonds represent fossil specimens, stars represent the average value for each column. For PCs in which the upper and lower dotted lines run in parallel, the overall range is similar. For PCs in which the upper and lower dotted lines are diverging, the range is larger in the fossil specimens and 33 roughly resembles myiodactylid-type larvae. One therefore could further conclude that there are two types of larvae in the modern fauna, and two types of rather similar larvae in the Cretaceous. This would indicate no change in diversity in the larval forms of Nymphidae over time, at least no significant one.

Yet, as the plots well reveal, this is not the case. Instead, the fossil larvae separate recognisably from the extant larvae. Interestingly, the only fossil larvae that closely overlap with modern forms are the ones with a large and a small tooth per mandible.

\section{Occupation of morphospace}

When comparing the range of the different principal components (Fig. 11), a pattern becomes apparent: In PC1, PC3, PC7 and PC8, the range occupied by fossils is larger than that of the extant forms. This is especially unusual as the sample size for the fossils is smaller. In PC2, PC4, PC5 and PC6, the occupied range is roughly similar. Also, here it needs to be considered that the sample size of the fossils is smaller than of the extant material.

We could potentially apply a sample size correction (as in Haug et al. 2020), which would mean that the range occupied by the fossil forms is effectively larger in all principal 


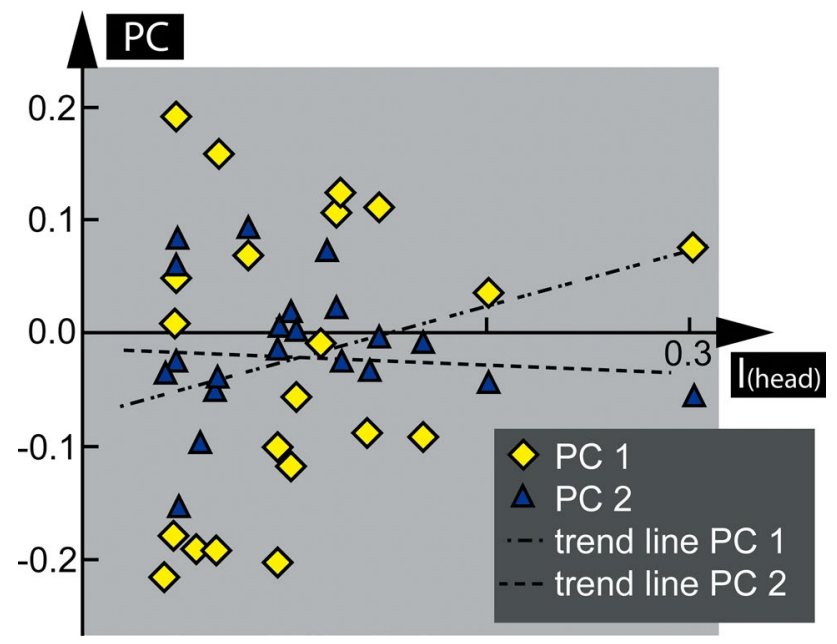

Fig. 12 PC1 and PC2 plotted against head length (1 (head)). There is no recognisable correlation between size and shape of the head (PC1: $R^{2}=0.06 ; \mathrm{PC} 2: R^{2}=0.005$ )

components, yet as the difference is already that apparent, this appears not to be necessary.

The comparison here is more simplified than the one performed for Psychopsidae (Haug et al. 2020). This is caused by the extremely low sample size for the Eocene, consisting of only one specimen. Yet, at least we can effectively compare the extant fauna with the Cretaceous one. While we have not further differentiated the Eocene larva from the Cretaceous ones, it becomes apparent that the Eocene larva does not occupy an outlier position. It falls into the range outlined by the Cretaceous larvae and does therefore not introduce an artefact.

As already outlined, a simple comparison of types would provide the impression that we have more or less the same diversity in the Cretaceous and the modern fauna. The quantitative analysis indeed indicates that the morphological diversity of larvae of Nymphidae was higher in the past. This further indicates that also the ecological functions fulfilled by these larvae were likely larger in the past than they are today.

The modern representatives of the group Nymphidae are restricted to Australasia, with the most Northern occurrence in the Philippines (Shi et al. 2015). Although the amber occurrences in Myanmar lie further north nowadays, during the Cretaceous, they were probably not further north than the Philippines are today. However, the single specimen from Baltic amber indicates a further Western distribution. Fossils of adults point to an even wider distribution (see also Shi et al. 2015). This already indicates that the modern distribution may represent a relictual distribution. A more restricted modern-day distribution would be compatible with a more restricted modern-day ecological diversity.

\section{New reconstruction for the ground pattern of Nymphidae}

While we focus herein on changes of the diversity over time, we can also make additional observations that influence our reconstruction of the ground pattern of Nymphidae. Badano et al. (2018: 10, fig. 4) reconstructed the ground pattern state for larvae of Nymphinae as being camouflagers. Character distribution on the phylogenetic tree indicates that this is an autapomorphy of Nymphinae. In this respect, specimens 31 and 33 are interesting. These specimens resemble myiodactylid-type larvae in their mandible shape and the head shape. Although many details of these are not available (hence prohibiting to include them into the matrix provided by Badano et al. 2018), it seems likely that these similarities represent shared derived characters, indicating that these two fossils are larvae of derivatives of the lineage of Myiodactylinae, or at least their direct stem-lineage.

Both of these larvae are heavily covered with debris, indicating that they used this debris as camouflage. This makes it likely that the ground pattern condition of larvae of Nymphidae is indeed camouflage behaviour and that the absence of this behaviour in modern larvae of Myiodactylinae could be a derived condition.

\section{A further piece to the puzzle}

Haug et al. (2020) have shown a higher diversity for larval forms of Psychopsidae, the group of silky lacewings. For larvae of thread-winged lacewings, Haug et al. (accepted) show that possible fossil forms differ significantly from modern ones, making a comparison challenging, but clearly indicating the loss of some larval forms since the Cretaceous. For Nymphidae, we now find a similar pattern as for Psychopsidae.

It appears likely that the entire group of lacewings, Neuroptera, was more successful in the past. It has often been assumed that the group Neuroptera was part of the early radiation of Holometabola. Yet, this statement also gives the impression that these animals are somehow ancient-looking. Quite on the contrary, the larvae clearly derive strongly from a plesiomorphic larval appearance, effectively being highly derived, specialised predators.

Analysing the morphology of these larvae clearly provides an opportunity to compare diversity of morphology and indirectly of ecological function. While there is the general notion of a decrease in diversity in Neuroptera, quantifying pure taxonomic properties cannot provide a clear support for that. For Nymphidae, more extant species are still known than fossil ones (Shi et al. 2015). The work herein, hence, provides another important piece to the puzzle for inferring diversity changes over time. 
Supplementary Information The online version contains supplementary material available at https://doi.org/10.1007/s12542-021-00550-1.

Acknowledgements We thank two anonymous reviewers and the Editor-in-Chief Mike Reich for helpful comments. The study is kindly supported by the Volkswagen Foundation with a Lichtenberg Professorship to JTH. CH is grateful for funding via the LMUexcellent Junior Researcher Fund and an award for equal opportunities for women in research of the LMU Munich. Serita van der Wal is kindly funded by the Deutscher Akademischer Austauschdienst (DAAD; Research Grants-Doctoral Programmes in Germany, Reference no. 91693832). J. Matthias Starck is thanked for long-time support. We thank all people providing free software. This is LEON publication \# 19.

Funding Open Access funding enabled and organized by Projekt DEAL.

Open Access This article is licensed under a Creative Commons Attribution 4.0 International License, which permits use, sharing, adaptation, distribution and reproduction in any medium or format, as long as you give appropriate credit to the original author(s) and the source, provide a link to the Creative Commons licence, and indicate if changes were made. The images or other third party material in this article are included in the article's Creative Commons licence, unless indicated otherwise in a credit line to the material. If material is not included in the article's Creative Commons licence and your intended use is not permitted by statutory regulation or exceeds the permitted use, you will need to obtain permission directly from the copyright holder. To view a copy of this licence, visit http://creativecommons.org/licenses/by/4.0/.

\section{References}

Aspöck, U., and H. Aspöck. 2007. Verbliebene Vielfalt vergangener Blüte. Zur Evolution, Phylogenie und Biodiversität der Neuropterida (Insecta: Endopterygota). Denisia 20: 451-516.

Badano, D., U. Aspöck, H. Aspöck, and P. Cerretti. 2017. Phylogeny of Myrmeleontiformia based on larval morphology (Neuropterida: Neuroptera). Systematic Entomology 42: 94-117.

Badano, D., M.S. Engel, A. Basso, B. Wang, and P. Cerretti. 2018. Diverse Cretaceous larvae reveal the evolutionary and behavioural history of antlions and lacewings. Nature Communications 9: art. 3257.

Braig, F., J.T. Haug, M. Schädel, and C. Haug. 2019. A new thylacocephalan crustacean from the Upper Jurassic lithographic limestones of southern Germany and the diversity of Thylacocephala. Palaeodiversity 12: 69-87.

Brauer, F.M. 1867. Beschreibung und Verwandlung des Dendroleon pantherinus Fbr. und Vergleich der bis jetzt bekannten Myrmeleoniden- und Ascalaphiden-Larven. Verhandlungen der Kaiserlich-Königlichen Zoologisch-Botanischen Gesellschaft in Wien 17: 963-966.

Cruickshank, R.D., and K. Ko. 2003. Geology of an amber locality in the Hukawng Valley, northern Myanmar. Journal of Asian Earth Sciences 21: 441-455.

Froggatt, W.W. 1902. Notes on Australian Neuroptera and their lifehistories. Proceedings of the Linnean Society of New South Wales 27: $358-369$.

Froggatt, W.W. 1907. Australian insects, 1-449. Sydney: William Brooks \& Company Ltd.

Gallard, L. 1935. Notes on the life-history of the large Yellow Lacewing, Nymphes myrmeleonides. Australian Naturalist 9: 118-119.

Gepp, J. 1984. Erforschungsstand der Neuropteren-Larven der Erde (mit einem Schlüssel zur Larvaldiagnose der Familien, einer
Übersicht von 340 beschriebenen Larven und 600 Literaturzitaten), 183-239. In Progress in World's Neuropterology. (Proceedings of the 1st International Symposium on Neuropterology, 22-26 September 1980, Graz, Austria), eds. J. Gepp, H. Aspöck, and H. Hölzel, 1-265. Graz: Privately printed.

Hagen, H. 1873. Die Larven von Ascalaphus. Stettiner Entomologische Zeitung 34: 33-62.

Haug, C., A.F. Herrera-Flórez, P. Müller, and J.T. Haug. 2019a. Cretaceous chimera - an unusual 100-million-year old neuropteran larva from the "experimental phase" of insect evolution. Palaeodiversity 12: 1-11.

Haug, C., K.R. Shannon, T. Nyborg, and F.J. Vega. 2013a. Isolated mantis shrimp dactyli from the Pliocene of North Carolina and their bearing on the history of Stomatopoda. Bolétin de la Sociedad Geológica Mexicana 65: 273-284.

Haug, G.T., V. Baranov, G. Wizen, P.G. Pazinato, P. Müller, C. Haug, and J.T. Haug. accepted. The morphological diversity of longnecked lacewing larvae (Neuroptera: Myrmeleontiformia). Bulletin of Geosciences.

Haug, G.T., C. Haug, P.G. Pazinato, F. Braig, V. Perrichot, C. Gröhn, P. Müller, and J.T. Haug. 2020. The decline of silky lacewings and morphological diversity of long-nosed antlion larvae through time. Palaeontologia Electronica 23(2): a39.

Haug, J.T., and C. Haug. 2019. Beetle larvae with unusually large terminal ends and a fossil that beats them all (Scraptiidae, Coleoptera). PeerJ 7: e7871.

Haug, J.T., C. Haug, and M. Ehrlich. 2008. First fossil stomatopod larva (Arthropoda: Crustacea) and a new way of documenting Solnhofen fossils (Upper Jurassic, Southern Germany). Palaeodiversity 1: 103-109.

Haug, J.T., C. Haug, V. Kutschera, G. Mayer, A. Maas, S. Liebau, C. Castellani, U. Wolfram, E.N.K. Clarkson, and D. Waloszek. 2011. Autofluorescence imaging, an excellent tool for comparative morphology. Journal of Microscopy 244: 259-272.

Haug, J.T., C.H.G. Müller, and A. Sombke. 2013b. A centipede nymph in Baltic amber and a new approach to document amber fossils. Organisms Diversity \& Evolution 13: 425-432.

Haug, J.T., P. Müller, and C. Haug. 2018. The ride of the parasite: A 100-million-year old mantis lacewing larva captured while mounting its spider host. Zoological Letters 4: art. 31.

Haug, J.T., P. Müller, and C. Haug. 2019b. A 100-million-year old predator: A fossil neuropteran larva with unusually elongated mouthparts. Zoological Letters 5: art. 29.

Haug, J.T., P. Müller, and C. Haug. 2019c. A 100-million-year old slim insectan predator with massive venom-injecting stylets: A new type of neuropteran larva from Burmese amber. Bulletin of Geosciences 94: 431-440.

Henry, C.S. 1972. Eggs and rapagula of Ululodes and Ascaloptynx (Neuroptera: Ascalaphidae): A comparative study. Psyche: A Journal of Entomology 79(1-2): 1-22.

Herrera-Flórez, A.F., F. Braig, C. Haug, C. Neumann, J. Wunderlich, M.K. Hörnig, and J.T. Haug. 2020. Identifying the oldest larva of a myrmeleontiformian lacewing: A morphometric approach. Acta Palaeontologica Polonica 65: 235-250.

Hörnig, M.K., C. Kiesmüller, P. Müller, C. Haug, and J.T. Haug. 2020. A new glimpse on trophic interactions of 100-million-year old lacewing larvae. Acta Palaeontologica Polonica 65: 777-786.

Liu, X., G. Shi, F. Xia, X. Lu, B. Wang, and M.S. Engel. 2018. Liverwort mimesis in a Cretaceous lacewing larva. Current Biology 28(9): 1475-1481.

Liu, X., W. Zhang, S.L. Winterton, L.C. Breitkreuz, and M.S. Engel. 2016. Early morphological specialization for insect-spider associations in Mesozoic lacewings. Current Biology 26(12): $1590-1594$. 
MacLeod, E.G. 1964. A comparative morphological study of the head capsule and cervix of larval Neuroptera (Insecta). Doctoral dissertation, Harvard University.

MacLeod, E.G. 1970. The Neuroptera of the Baltic Amber. I. Ascalaphidae, Nymphidae, and Psychopsidae. Psyche: A Journal of Entomology 77(2): 147-180.

McLachlan, R. 1871. An attempt towards a systematic classification of the family Ascalaphidae. Zoological Journal of the Linnean Society 11: 219-276.

New, T.R. 1982. The larva of Nymphes Leach (Neuroptera: Nymphidae). Neuroptera International 2(2): 79-84.

New, T.R. 1983. Some early stages of Osmylops (Neuroptera: Nymphidae). Systematic Entomology 8(1): 121-126.

New, T.R. 1989. Planipennia, Lacewings. Handbuch der Zoologie, Vol. 4 (Arthropoda: Insecta), Part 30, 1-132. Berlin: Walter de Gruyter.

New, T.R. 1991. Neuroptera (lacewings). In The Insects of Australia, Vol. 1. $2^{\text {nd }} e d$., ed. I.D. Naumann, 525-542. Melbourne: Melbourne University Press.

New, T.R., and K.J. Lambkin. 1989. The larva of Norfolius (Neuroptera: Nymphidae). Systematic Entomology 14: 93-98.

Oswald, J.D., and R.J.P. Machado. 2008. Biodiversity of the Neuropterida (Insecta: Neuroptera, Megaloptera, and Raphidioptera). In Insect Biodiversity: Science and Society, vol. 2, eds. R.G. Foottit and P.H. Adler, 627-672. Hoboken: Wiley.

Pérez-de la Fuente, R., X. Delclos, E. Penalver, and M.S. Engel. 2016. A defensive behavior and plant-insect interaction in Early Cretaceous amber - the case of the immature lacewing Hallucinochrysa diogenesi. Arthropod Structure \& Development 45(2): 133-139.

Pérez-de la Fuente, R., X. Delclòs, E. Peñalver, M. Speranza, J. Wierzchos, C. Ascaso, and M.S. Engel. 2012. Early evolution and ecology of camouflage in insects. Proceedings of the National Academy of Sciences 109(52): 21414-21419.

Pérez-de la Fuente, R., M.S. Engel, D. Azar, and E. Peñalver. 2019. The hatching mechanism of 130-million-year-old insects: An association of neonates, egg shells and egg bursters in Lebanese amber. Palaeontology 62(4): 547-559.

Perez-de la Fuente, R., M.S. Engel, X. Delclòs, and E. Penalver. 2020. Straight-jawed lacewing larvae (Neuroptera) from Lower
Cretaceous Spanish amber, with an account on the known amber diversity of neuropterid immatures. Cretaceous Research 106: art. 104200.

Pérez-de la Fuente, R., E. Peñalver, D. Azar, and M.S. Engel. 2018. A soil-carrying lacewing larva in Early Cretaceous Lebanese amber. Scientific Reports 8(1): art. 16663.

Riek, E.F. 1970. Neuroptera (Lacewings). In Insects of Australia: A textbook for students and research workers, 472-494. Melbourne: Melbourne University Press.

Ross, E.S. 1953. Insects close up: A pictorial guide for the photographer and collector featuring 125 photographs and drawings, 1-80. Los Angeles: University of California Press.

Shi, C., S.L. Winterton, and D. Ren. 2015. Phylogeny of split-footed lacewings (Neuroptera, Nymphidae), with descriptions of new Cretaceous fossil species from China. Cladistics 31(5): 455-490.

Tauber, C.A., M.J. Tauber, and G.S. Albuquerque. 2003. Neuroptera (lacewings, antlions). In Encyclopedia of Insects, eds. V.H. Resh and R.T. Cardé, 695-707. San Diego: Academic Press.

Tillyard, R.J. 1926. The Insects of Australia and New Zealand, 1-560. Sydney: Angus and Robertson.

Van der Weele, H.W. 1908. Ascalaphiden. Collections Zoologiques du Baron Edm. de Selys Longchamps. Catalogue Systématique et Descriptif 8: 1-326.

Wang, B., F. Xia, M.S. Engel, V. Perrichot, G. Shi, H. Zhang, J. Chen, E.A. Jarzembowski, T. Wappler, and J. Rust. 2016. Debris-carrying camouflage among diverse lineages of Cretaceous insects. Science Advances 2(6): e1501918.

Weidner, H. 1958. Einige interessante Insektenlarven aus der Bernsteininklusen-Sammlung des Geologischen Staatsinstituts Hamburg (Odonata, Coleoptera, Megaloptera, Planipennia). Mitteilungen aus dem Geologischen Staatsinstitut in Hamburg 27: 50-68.

Xia, F., G. Yang, Q. Zhang, G. Shi, and B. Wang. 2015. Amber: Life Through Time and Space, 1-197. Beijing: Science Press.

Zhang, W.W. 2017. Frozen dimensions. The fossil insects and other invertebrates in amber, 1-692. Chongqing: Chongqing University Press. 